\title{
La construcción europea, en la perspectiva del siglo XX
}

\section{Francisco Villacorta Baños}

Arbor CLXX, 669 (Septiembre 2001), 1-41 pp.

\section{Introducción}

«Dans ces débuts (de las negociaciones para la creación del Mercado Común), un fonctionnaire britannique assistait aussi aux séances... Jamais son digne représentant n'ouvrait la bouche, sinon pour y insérer sa pipe. Enfin, un jour, il demande la parole à la surprise générale. C'était pour tenir le discours d'adieu suivant:

«Monsieur le Président, Messieurs. Je voulais vous remercier sincèrement de votre hospitalité et vous indiquer qu'elle va cesser à partir d'aujourd'hui. En effet, je regagne Londres. Fonctionnaire sérieux, il me gêne de perdre mon temps et de ne pas justifier le modeste argent que me verse mon Gouvernement. J'ai suivi avec intérêt et sympatie vos travaux. Je dois vous dire que le futur traité dont vous parlez et que vous êtes chargé d'élaborer:

a) n'a aucune chance d'être conclu;

b) s'il est conclu, n'a aucune chance d'être ratifié;

c) s'il est ratifié, n'a aucune chance d'être appliqué.

Nota bene: S'il l'était, il serait d'ailleurs totalement inaceptable pour la Grande-Bretagne. On y parle d'agriculture, ce que nous n'aimons pas, de droits de douane, ce que nous récusons, et d'institutions, ce qui nous fait horreur. Monsieur le Président, Messieurs, au revoir et bonne chance»

DENIAU, Jean François: La découverte de l'Europe. Paris, edic. de 1994, pp. 54-55. 


\title{
Más de 300 empresarios británicos firman un anuncio en la prensa con el lema «Europa sí, euro no»
}

\begin{abstract}
«No deseamos que el Reino Unido quede atrapado en el euro, que esto lleve a impuestos más altos, que perjudique el desempleo», señalan los empresarios en el anuncio. «Nuestra economía nunca estuvo tan bien como ahora. Es por ello que encuestas de las (firmas) ICM y MORI muestran que la mayoría del sector empresarial dice sí a Europa y no al euro», añade.
\end{abstract}

El Pais, 7 de septiembre de 2000

Pocas dudas ofrece hoy en día la existencia de una entidad internacional, política y jurídica cobijada bajo el nombre de Europa, lo cual no es una constatación tan evidente como parece, dado que tal existencia implica romper algunos esquemas convencionales acerca de las formas de ser que hasta aquí se han desplegado en el plano internacional: En concreto, tal realidad implica sumar algo a las adjetivaciones abstractas de carácter geográfico o cultural, que han dado por supuesto desde antaño tal naturaleza europea -la Europa como hecho contrastado en geografía y en civilización de que hablaba el historiador Duroselle ${ }^{1}$ - pero también restarlo a las representaciones convencionales que se tienen de la soberanía en los Estados-Nación históricos, ya que éstos siguen gozando de innegable salud en el interior del nuevo ente político.

Pocas dudas existen hoy asimismo sobre su asentamiento, salvo catástrofes imprevistas, entre las realidades cotidianas de los ciudadanos de las viejas naciones integrantes, por mucho que los barómetros de la temperatura europeísta oscilen considerablemente y en algunas zonas del continente apenas alcancen valores mínimos de confortabilidad democrática. Apenas cabe duda, en definitiva, de que Europa existe políticamente, aunque en sus engranajes políticos se interfieran, y en apariencia cada vez con más vigor, los dos haces de fuerza -nacionalismo político e internacionalismo económico- que han acotado históricamente su trayectoria.

Pero este tipo de pulsiones contradictorias forman parte del conjunto de peripecias que han conformado la geometría irregular de la construcción europea. Como en los años cruciales del nacimiento político propiamente dicho de Europa, cuando el europeísta suizo Denis de Rougemont exponía la paradoja de que Europa, «nunca antes tan amenazada, tan dividida ante el peligro», estaba deshaciéndose, pero al mismo tiempo, "por primera vez en toda su larga historia» estaba 


\section{La construcción europea, en la perspectiva del siglo XX}

construyéndose conscientemente ${ }^{2}$, también ahora, después de décadas de construcción de un mercado unido y de unas instituciones europeas comunes, aparece el proceso de unión más discutido y problemático que nunca, si nos atenemos a las manifestaciones más llamativas de las opiniones públicas europeas.

Tal contradicción no es sino aparente. Sírvanos para desvelarla las citas que encabezan esta introducción y el país, de entre los grandes del continente, más reticente a la idea de una «nación» europea. Lo que en 1958 resultaba inaceptable -la apertura de un proceso de integración económica europea- se aplica en el 2000 al paso más audaz emprendido hasta ahora en ese camino: el euro. Se trata, pues, de periódicas crisis de crecimiento. Esto significa en términos generales que a cada paso -discutido- de unión europea le ha seguido una fase de asentamiento y negociación, incluso de retroceso aparente, para afirmar los pies sobre una plataforma común aceptable a las diversas concepciones de la idea de Europa. Pero siempre -al menos hasta el momento presente- el paso siguiente ha interiorizado como algo definitivamente adquirido -milagros del método comunitario- lo que antes resultaba problemático. Si en la fase europea abierta entre 1986 y 1992 con el Acta Única y el tratado de Maastricht los debates se han agudizado es simplemente porque por primera vez el futuro de la Unión no se justifica a partir de la lógica creada por su propia historia, sino que se trata de crear una forma política nueva, que toca a partes esenciales de lo que constituye la soberanía de las naciones y que es preciso construir conjuntamente por los países embarcados en el proyecto a partir de una ruptura con los métodos utilizados hasta el momento: el método Monnet de pequeños pasos y el procedimiento de negociaciones de carácter técnico, entabladas por personas legitimadas democráticamente, pero sustraídas al debate de las opiniones públicas europeas. Por primera vez, pues, Europa intenta construirse con los procedimientos todos que integran la democracia política, cosa, como es obvio, que propicia la presencia del tema europeo en el debate público ${ }^{3}$. La índole de los problemas planteados entre uno y otro proceso es lo que se intenta someramente esbozar aquí desde una perspectiva impresionista, que combina la mirada cruzada desde diferentes escenarios europeos y la visión española de lo europeo, más genérica, más prospectiva, dado su alejamiento por razones bien conocidas de las etapas concretas de diseño de una Europa posible.

Es preciso recalcar, sin embargo, antes de concluir este preámbulo, que este conjunto de trabajos no intentan trazar una historia de las Comunidades europeas en sentido estricto ${ }^{4}$. Algo contienen de ese pro- 
ceso ciertamente, pero si hubiera que darles una imagen unitaria, la más certera sería la de una errática navegación por los brazos y los meandros de un caudal histórico más amplio que los particulares de la Europa unida: en última instancia, a los que hacen referencia a una hipotética identidad colectiva europea y a los canales de comunicación pasados y presentes a partir de los que es posible imaginarla. La imagen no es nueva. Pertenece al pedagogo checo Comenio, víctima él mismo de las luchas político-religiosas de la Europa del siglo XVII, cuando en su obra Praefacio ad Europeos, de 1645, escribía: «Nosotros los Europeos debemos considerarnos como viajeros embarcados en un mismo navío» ${ }^{5}$. Todo hace pensar que esa tarea resulta tan incierta -tan sugestiva por ello mismo- como la propia tarea de organizar un futuro unido y construir su sentido racional. Hace ya unos años algunos historiadores de diversos países europeos, en el marco de los programas de investigaciones patrocinados por la Comisión Europea, se plantearon la tarea de reflexionar sobre algunas de estas cuestiones -Identité et conscience européennes au XXe siècle fue el título genérico- y sus resultados - «la Europa de los historiadores»- tienen ese mismo cariz de lo provisional y lo prospectivo que ha sido el de las propias instituciones europeas. Nada en uno y otro campo es definitivo y firme, pero todo tiene al mismo tiempo la existencia inquebrantable que goza lo construido sobre principios racionales y democráticos, en permanente equilibrio entre los diversos compromisos sobre los que se ha ido diseñando la idea de Europa. Que en síntesis han sido los siguientes: el imperativo básico de construir un espacio de paz donde antes se había desarrollado la dialéctica del equilibrio/supremacía de las naciones, el de disciplinar y racionalizar las fuerzas de las economías nacionales para sentar sobre ellas una prosperidad económica compartida en beneficio de ciudadanos y territorios, el de equilibrar los legítimos intereses de los aún reticentes nacionalismos integrantes de la unión y, finalmente, el de moderar la lógica burocrática de las propias instituciones europeas. Con lo que ello tiene a la vez de positivo y problemático, aunque Europa no fuese más que esto, razones múltiples habría para analizar como historiadores, y aun para desear como ciudadanos, el crecimiento pujante de esa conciencia de ciudadanía europea, cuyo déficit tanto se lamenta hoy en día por parte de los federalistas europeos ${ }^{6}$.

\section{Europa como utopía}

Bien se puede decir que históricamente los principios más permanentes vinculados a la utopía de la unión continental han sido el de 


\section{La construcción europea, en la perspectiva del siglo XX}

la paz entre las naciones europeas y el del libre desarrollo de sus intercambios económicos. Como contrapunto de la realidad histórica secular de sus relaciones políticas y comerciales, siempre conflictivas, diversos hombres de la comunidad cultural europea -y que, como ya señaló Ortega y Gasset, fue europea antes de cristalizar en las modulaciones nacionales ${ }^{7}$ - soñaron en diferentes épocas y desde diferentes geografías la unión continental como un imperativo moral de concordia entre los hombres del continente. William Penn, el Abad de Saint Pierre, Rousseau o Kant fueron algunos de ellos ${ }^{8}$. Desde el siglo XIX además Inglaterra añadió a esa utopía de paz otra económica: la aritmética moral del utilitarismo librecambista, que había de dar justicia a cada uno y prosperidad a todos. Paz y librecambismo están tras la convocatoria del Congreso de la Paz de 1849, después de las conmociones revolucionarias del año anterior, presidido por Victor Hugo, de donde proceden sus proféticas palabras sobre la futura Europa unida: días vendrán -vino a decir- en que no habrá en Europa otro campo de batalla que el de los mercados, las ideas y los votos. Pero no fueron estos principios los que terminaron imponiéndose en la realidad de la política continental, sino el de la nación y con ella la permanencia de los principios de la razón de Estado, de la realpolitik y del nacionalismo económico, ahora subordinados al engrandecimiento del Estado y de la nación liberal, como antaño lo había estado a los intereses y al prestigio de la dinastía monárquica. Las iniciativas de concordia continental quedaron vinculadas así a la búsqueda, desde diferentes iniciativas públicas y privadas, de mecanismos de desarme y de instrumentos de arbitraje internacional que recompusiesen los pedazos de un derecho público europeo hecho jirones. La creación en 1868 de la Liga Internacional de la paz, editora del diario Los Estados Unidos de Europa, la constitución en 1873 del Instituto de Derecho Internacional de Gante, las sucesivas convocatorias de los Congresos de la Paz, las Conferencias de la Paz de La Haya de 1899 y 1904, fueron, todas ellas, iniciativas que, a despecho de su carácter internacionalista en la mayor parte de los casos, bien puede decirse que significaron una decisiva contribución a la genealogía del europeísmo en la medida en que esta toma de conciencia del déficit político y moral que significaban los enfrentamientos bélicos sólo podía entenderse plenamente en la consideración del continente europeo como un todo.

La primera gran guerra europea tuvo en este proceso un impacto decisivo porque significó, más allá de sus implicaciones en el terreno político, militar y económico, un profundo choque en la conciencia del mundo occidental, que pareció poner drásticamente en cuestión la coar- 
tada moral que enmascaraba el expansionismo de la civilización europea. Si desde el último tercio del siglo XIX venía difundiéndose entre los países europeos una cierta concepción darwinista del poder nacional, que justificaba su expansión «civilizadora» lo mismo frente a sociedades primitivas que frente a civilizaciones antiquísimas, e incluso frente a ciertos países europeos en decadencia, especialmente del área mediterránea, entre los que se incluía España, desde ahora el estigma de la barbarie y la decadencia pareció extenderse, junto con los desastres de la guerra, al conjunto del mundo occidental. Pocas categorías tuvieron mayor impacto en esta época que la de decadencia. La obra del historiador alemán Oswald Spengler: La Decadencia de Occidente, publicada entre 1918 y 1922 puede ser considerada su emblema. Pero en esa misma órbita pueden situarse las de Albert Demangeon: La Decadencia de Europa (1920), André Siegfried: La crisis de Europa (1922), Nicolai Berdiaeff: Una nueva Edad Media (1926), Henri Massis: La defensa de Occidente y Ortega y Gasset: La rebelión de las masas (1929), entre otras numerosas ${ }^{9}$.

Toda esta nueva visión del mundo europeo significó un importante cambio en el enfoque de los asuntos europeos en el momento de la paz. En el terreno diplomático, el resultado inicialmente más esperanzador fue la Sociedad de Naciones -organismo internacional, aunque las cuestiones europeas ocupasen en la práctica una parte importante de sus actividades- que se convirtió pronto en el centro de operaciones de todos los proyectos de cooperación pólítica, económica y cultural de entreguerras y que abrió el cauce en Europa a la «nueva diplomacia» estadounidense, formulada por el entonces presidente Wilson en términos de internacionalización de los asuntos europeos y democracia política $^{10}$. No resulta difícil verlo en este sentido, lo mismo que el conjunto de la época, como un ensayo general de las cuestiones cruciales, y de sus tentativas de abordarlas, que se impondrán de forma aún más urgente en la segunda postguerra mundial y que abrirán la vía de las instituciones propiamente europeas. La Sociedad de Naciones fue, en efecto, el órgano de referencia de una diplomacia multilateral que por un momento pareció cerrar las heridas dejadas por la guerra europea en la cuestión de las reparaciones (plan Dawes, 1924) y de las fronteras alemanas occidentales (tratados de Locarno, 1925), buscando pactos regionales semejantes en otras zonas europeas en conflicto, poniendo en marcha proyectos de desarme y de entente económica y estableciendo lo que pareció un compromiso mundial de estabilidad y seguridad colectiva (pacto Briand-Kellogg, 1928).

Un segundo fenómeno decisivo en el desarrollo de la conciencia europea de esta época fue el pacifismo. Las iniciativas de acuerdos 


\section{La construcción europea, en la perspectiva del siglo XX}

regionales o continentales de paz o de unión europea o regional, incluidas las tentativas de colaboración franco-alemana, fueron numerosas: soluciones, por mencionar solo algunas, de unión occidental, como la propuesta por el consejero de la presidencia norteamericana, Walter Lippmann, y otras destacadas personalidades del viejo y del nuevo continente ${ }^{11}$; soluciones de unión regional europea (la Mitteleuropa, la Federación danubiana, la Entente balcánica); organismos de colaboración y distensión social entre países, como el Comité franco-alemán de Información y Documentación, un organismo de amplia representatividad social, creado con el objetivo de proporcionar informaciones claras y controladas sobre cada uno de los dos países para evitar suspicacias y restablecer la confianza entre ellos ${ }^{12}$. De entre todo este extenso movimiento social fue, sin duda, el de orientación declaradamente europeísta el que adquirió mayor relieve público. Su expansión se encuentra ligado al conde Coudenhove-Kalergi, cosmopolita «europeo» por sus orígenes familiares y por sus opciones vitales ${ }^{13}$, como lo serán más tarde otros grandes pioneros de Europa. En 1922 crea el movimiento Unión Paneuropea y al año siguiente publica su libro Pan-Europa, manifiesto de unión confederal que preconiza en forma de utopía buena parte de los objetivos mucho más tarde plasmados en la Europa real: una unión aduanera, una moneda común, una alianza militar, un tribunal de conflictos intereuropeos, una colaboración política en amplios dominios sectoriales, especialmente en el cultural, y una histórica reconciliación franco-alemana. Ampliamente difundido por toda Europa, su amplio apoyo en los medios políticos y, especialmente, en los culturales hizo de él, y de su revista Pan-Europa, uno de los más influyentes centros de difusión de la conciencia europeísta, cuyos efectos perdurarán hasta las etapas decisivas de la Europa real en la segunda postguerra ${ }^{14}$.

Menos conocidos hasta hace relativamente poco tiempo han sido los intentos de creación en esta época de una economía que podría denominarse europea, capaz de garantizar la prosperidad general obviando los desastrosos efectos de la desaforada concurrencia nacionalista que había estado detrás de los pasados acontecimientos bélicos. En propiedad, no se trataba tanto en este momento de poner en práctica un proyecto que tocase las decisiones de política económica de las naciones europeas como de favorecer los impulsos de convergencia y colaboración que se habían ido desarrollado en el libre juego de las economías continentales: en la internacionalización de las inversiones, en la organización vertical de los sectores productivos de las distintas economías nacionales, en los convenios y acuerdos sindicados continentales de distintas ramas de la producción. Eran, conforme lo han 
expresado las investigaciones recientes sobre el tema, una concordancia sobre la producción más que sobre el mercado ${ }^{15}$. En definitiva, si patentes estaban los motivos de desequilibrio y conflicto económico que tendían al enfrentamiento entre países, se podía decir también que en este campo Europa existía de algún modo como relación e interdependencia en todos aquellos fenómenos esenciales de la realidad económica de entreguerras, que se pueden resumir en los conceptos de internacionalización y concentración de los distintos sectores productivos.

Algunos pioneros hombres de empresa europeos vieron con claridad los costes y las ventajas de una tal alternativa. Las investigaciones recientes han sacado a la luz las iniciativas, por ejemplo, de Emile Mayrisch, de la acería luxemburguesa ARBED, para la creación en 1926 de la Entente internacional del Acero entre empresas del sector de Bélgica, Francia, Luxemburgo, Sarre y Alemania, claro antecedente de la posterior CECA. Igualmente, han destacado las iniciativas del industrial y político francés Jean Loucheur a favor de una liga económica de países europeos, los proyectos del ingeniero Dannie N. Heineman de establecer a escala europea un banco central, una comisión de libre comercio y un plan de ferrocarriles, y otros de parecido carácter: los del inglés Arthur Salter de una unión aduanera europea, la Unión económica y aduanera europea del movimiento Pan-Europa o los Comités de Cooperación europea.

No es posible olvidar, por último, la intervención, siempre difícil de ponderar en el terreno de las realidades políticas, pero sin duda actuante en el más amplio de la conciencia pública, de los intelectuales europeístas, desde Paul Valery a Ortega y Gasset, desde Carlo Sforza a Jules Romains, desde el conde Hermann von Keyserling a Julien Benda. De Paul Valery se conoce el poético epitafio para la gran vuelo de la civilización europea del siglo XIX: "Ahora ya sabemos que somos mortales» ${ }^{16}$. A Ortega y Gasset se debe una consideración de gran luminosidad histórica: Europa es en derecho, en religión, en organización política, en sociedad, en arte, una condición continental anterior a las singularidades nacionales. La propia Sociedad de Naciones patrocinará este encuentro intelectual europeo al crear en su seno una Comisión internacional de cooperación intelectual, en la que, a pesar de sus credenciales, destacaba el «objetivo principal» de desarrollar «una colaboración intelectual en Europa y contribuir al acercamiento de los pueblos, condición del mantenimiento de la paz» ${ }^{17}$.

Todos estos factores confluirán en los años finales de la década de los veinte, cuando el fantasma de la recesión económica general, del retorno al nacionalismo económico y de las crisis políticas en Ale- 


\section{La construcción europea, en la perspectiva del siglo XX}

mania, con Hitler ya a las puertas del poder, amenace con quebrar los precarios compromisos políticos y económicos contraidos entre las naciones europeas y con convertir en humo las buenas intenciones pacifistas y europeístas de políticos, intelectuales y empresarios europeos. "Unirse o morir» fue la formulación dramática de esta nueva situación europea enunciada por el intelectual francés Gaston Riou en su libro de ese título fechado 1929. Y las iniciativas en esta dirección tuvieron asimismo idéntico sentimiento de compromiso urgente si se querían conjurar los peligros que amenazaban la paz europea. Un hombre como el intelectual francés Julien Benda, también europeo avant la lettre, en este caso por su decidido emplazamiento en una comunidad de valores racionales y «grecolatinos» que, en su opinión, trenzaban el hilo nunca roto de la tradición cultural occidental desde Atenas, publicó en 1933 sus Discursos a la nación europea que querían ser, al superponer el título sobre el que se puede considerar manifiesto fundador del nacionalismo alemán, los Discursos a la nación alemana (1808) del filósofo Fichte, el golpe de timón para la deriva nacionalista y romántica germánica en sus más extremistas acepciones que en aquellos momentos estaba comenzando a ganar la batalla en Europa.

El episodio público europeísta más importante de esta época fue, sin embargo, el memorándum conocido por el nombre del entonces ministro de Asuntos Exteriores de la República Francesa, Aristide Briand, elaborado por el gobierno francés después del discurso de aquél en la sesión de la Sociedad de Naciones del 5 de septiembre de 1929 y presentado a los gobiernos de los distintos países europeos para evaluación e informe. En síntesis, se trataba de un proyecto de unión en el terreno económico especialmente, pero también en última instancia política, aunque respetuoso con las respectivas soberanías nacionales, sobre la base de «una especie de lazo federal», de un «lazo de solidaridad» entre los países del continente que les permitiese esbozar políticas comunes en campos diversos $\mathrm{y}$, en caso de necesidad, hacer frente a las circunstancias graves que pudieran presentarse. El memorándum, publicado en mayo de 1930, esbozada además un cuadro institucional somero - una Conferencia europea representativa de los Estados miembros, un Comité político deliberativo y consultivo, un Secretariadodel futuro marco político de la unión. Discurso y memorándum recibieron la atención inmediata de los diversos medios organizados de opinión europeísta, entusiastas por lo general hacia la propuesta. Mucho más, sin duda, que las respuestas oficiales de los gobiernos consultados, casi todas ellas reticentes hacia el proyecto en general o hacia aspectos parciales de él, bien por razones nacionalistas, bien por reticencias 


\section{Francisco Villacorta Baños}

hacia una nueva organización política, que podría significar además un peligro de fraccionamiento de la política de arbitraje y colaboración internacional que representaba la Sociedad de Naciones, bien con el pretexto de responsabilidades particulares extraeuropeas -colonias o ámbitos culturales- como fue el caso de España ${ }^{18}$. Todo ello fue lo que llevó a su retirada momentánea, confiando en contrapartida el estudio detallado de sus objetivos a una mucho menos vinculante Comisión de estudio para la unión europea, que desarrolló sus trabajos entre 1931 y 1932. Las circunstancias políticas ulteriores en Europa y la muerte del propio Briand en 1932 contribuirán a inutilizar por el momento sus tareas.

Porque, en efecto, la etapa política inmediata va a estar marcada por un cambio radical en las percepciones de todo tipo que constituían la tradición occidental desde hacía más de cien años, incluidas las menos alhagüeñas del imperialismo y de la balace of power. La supremacía de un país, Alemania, el espacio vital definido por la raza aria y, más adelante, la federación europea subordinada a estos principios fueron el nuevo escenario del futuro europeo a partir de 1933. Si acaso es posible percibir una nota significativa relativa el campo que nos ocupa es precisamente la de cobijar a esta nueva dinámica imperial bajo nombre substantivo de Europa, la Europa Nueva, vertebrada en una jerarquía de Estados satelizados en torno la idea del Imperio germánico ${ }^{19}$.

\section{Europa como realidad}

Casi todos los hilos del drama europeo de la primera postguerra van a desplegarse de nuevo, con vigor redoblado, sobre el escenario continental al concluir la guerra en 1945 . Pero esta vez bajo condiciones relativamente nuevas, que van a combinar la continuidad de las iniciativas, y ocasionalmente de los propios protagonistas, de carácter europeísta junto a circunstancias internacionales favorables a una colaboración europea de nuevo tipo. Yalta fue ciertamente muy diferente de Versalles en la medida en que, aun sin la radicalidad de los años posteriores de la guerra fría, pero preludiándola, consagraba una bipolaridad internacional en la que los territorios europeos se convertían en objeto de reparto -económico o político- entre las dos grandes potencias mundiales consagradas por la guerra: los EE UU, con Inglaterra como apéndice estratégico, y la Unión Soviética. Esta nueva circunstancia internacional fue, en conclusión, la definitiva para un porvenir europeo marcado en aquella reunión por una decidida voluntad de 


\section{La construcción europea, en la perspectiva del siglo XX}

borrar de raíz todo vestigio de nazismo, pero junto a ello, en contrapartida, por vagas promesas de autonomía y democratización de los países europeos liberados, que a nada comprometían y que desde luego, aunque pudiesen ser previsibles, no preludiaban necesariamente los diferentes conceptos de democracia que terminarán imponiéndose en ellos.

La tarea asumida por los políticos europeos de la postguerra fue ingente. Entre 1945, fin de la guerra, y 1948-51, en que se ponen en marcha las primeras instituciones propiamente europeas: la Organización europea de Cooperación económica (OECE), 1948, el Consejo de Europa, 1949 y la Comunidad europea del carbón y del acero (CECA), 1951, se desarrolla un intenso haz de declaraciones, iniciativas públicas y privadas y tentativas unilaterales de organizar un nuevo marco de relaciones políticas y económicas estables en Europa. W. Churchill fue el primero, de entre los grandes políticos que marcaron aquella etapa política, que se pronunció decididamente por un futuro de integración de las naciones europeas ${ }^{20}$. En absoluto su posición se emplazaba en la misma línea de pensamiento de los grandes europeístas del período, ya que, consecuente con la política tradicional inglesa al respecto, dejaba fuera del proyecto al propio Reino Unido, pero expresaba al menos la concordancia bastante generalizada sobre la empresa europeísta puesta en el candelero en aquellos días por numerosas iniciativas de diverso carácter en todo el continente. Algunos de ellos fueron: el United Europe Movement, creado a finales de 1946 por el propio yerno de Churchill, Duncan Sandys, el Conseil français pour l'Europe Unie, de 1947, Paneuropa-Union en Alemania, Europeesche Actie de 1945 en Holanda, los movimientos de orientación religiosa Pax Christi y Nouvelles Équipes Internationales, la Ligue européenne de Coopération économique, de 1946, la Union Parlementaire européenne fundada por el conde Coudenhove-Kalergi, el Comité international pour les Etats Unis socialistes d'Europe de 1947, convertido tres años después en el Mouvement socialiste pour les Etats Unis d'Europe, así como los comités que intentaron coordinar todo este amplio movimiento europeísta: la Union européenne des fédéralistes de 1946, el Comité international de coordination des mouvements pour l'unité européenne de 1947, presidido por Sandys y, después del Congreso europeísta de La Haya de 1948, el Movimiento Europeo $^{21}$.

No es el momento de mencionar al detalle los pasos concretos de cada una de estas iniciativas, que han merecido en los últimos años un interés creciente por parte de los historiadores hasta acumular un corpus bibliográfico ya copioso del movimiento europeísta. El objetivo 
concreto de esta reseña de la Europa real que se pone en marcha en estos años es el de subrayar sus líneas de fuerza y de fractura, aquellas que continúan concitando en la actualidad los debates más activos y las mayores inquietudes sobre el porvenir de la Unión. Intentaremos hacerlo a través de una sistematización de las coordenadas en que se desenvolvieron los objetivos generales, ya mencionados, del movimiento europeo: el establecimiento de una política de paz, que ante el avance irresistible de la guerra fría se convirtió en una política de seguridad y defensa de la Europa occidental, la coordinación continental de los proyectos de reconstrucción y desarrollo económico, igualmente constreñida por las mismas razones al marco occidental y campo de batalla desde el principio de las dos diferentes concepciones -que podemos denominar política y librecambista- de la unión continental; la política finalmente, dentro de este contexto internacional y económico, de reconciliación entre los países enfrentados en la reciente guerra y de organización de un sistema ponderado de relaciones capaz de romper la vieja realpolitik del equilibrio europeo. Junto a ello haremos referencia al factor institucional, es decir, a las modalidades de actuación dentro de las nuevas instituciones europeas -el método Monnet, el método comunitario- que han permitido, a pesar de todas sus limitaciones y deficiencias, un avance ininterrumpido en la integración de los países europeos tanto en los sectores clave de las políticas gubernamentales como en los mil y un campos de relaciones institucionales y personales gestionados por los ciudadanos europeos. Por último, apuntaremos algunos datos sobre el papel muy limitado de España en este proceso, el argumento que en definitiva nos ha impulsado a emplazar el conjunto de trabajos referidos a ella en el contexto histórico más amplio de la Europa posible, de las modalidades de la conciencia europea y del tejido social e institucional de experiencias de los pueblos europeos a partir de las que es posible imaginar en el futuro una sociedad en la que la acepción general europea prevalezca sobre las particulares de las naciones integrantes.

\section{La política de seguridad y defensa europea}

Un factor condicionante decisivo de la nueva política europea fue la aparición de la trama y los personajes de la guerra fría sobre el escenario de las relaciones internacionales desde antes incluso de concluir la guerra. Así, lo que pudo ser el ejercicio de audeterminación y democracia para los países europeos vagamente sugerido en Yalta se convirtió en un reparto de zonas de influencia y la subordinación, 


\section{La construcción europea, en la perspectiva del siglo XX}

a efectos de la política de seguridad y defensa de su parte occidental, al liderazgo de los EE UU. El concepto substantivo de Europa, es decir, el movimiento europeo propiamente dicho se identificará a partir de este momento con esta fracción occidental del continente.

La política del presidente norteamericano Truman de contención del comunismo tuvo, sin duda, efectos destacados en las vicisitudes de esta política. El primero, y de alcance más general, fue el de pensar los países europeos integrados de facto en una única comunidad, aunque no se le pretendiera dar ciertamente otro alcance que el comercial y defensivo. Si bien resulta difícil desligar ambos aspectos, a efectos expositivos dejaremos para más adelante el primero de ellos para seguir ahora el curso de la política de defensa y seguridad europea bajo el paraguas nuclear norteamericano. En marzo de 1948, a iniciativa británica, cinco países europeos (Inglaterra, Francia, Bélgica, Holanda y Luxemburgo, con la puerta abierta a la unión posterior de Italia y Alemania) firmaron el Pacto de Bruselas, acuerdo en síntesis defensivo ante la amenaza soviética, aunque algunas de sus cláusulas, a la postre nunca aplicadas enteramente, apuntasen hacia una colaboración intereuropea en materia económica y cultural, en un momento en que se debatían en el Congreso norteamericano las ayudas del plan Marshall para la reconstrucción y desarrollo europeo.

En realidad, el Pacto fue sólo una etapa hacia el tratado del Atlántico, creador de la OTAN, del año siguiente, un tratado y una organización ampliados inicialmente a dos países americanos (EE.UU. y Canadá), tres norteeuroeos (Dinamarca, Noruega e Islandia) y dos Meditarráneos (Italia y Portugal) -de inmediato se unirán Grecia y Turquía, 1952, y la República Federal Alemana, 1955- y compuestos, en su esquema básico, de un Consejo político, un Secretariado general y un Comité operativo militar ${ }^{22}$. Por este tratado, Europa asumía en síntesis una decisión extraordinariamente vinculante para su futura política de unión, incluso hasta nuestros días: la de confiar las cuestiones de su seguridad y defensa a un liderazgo extraeuropeo: Norteamérica. No fue desde luego un asunto unánimemente asumido por parte de los países europeos, pero sí el que suponía mayores ventajas en la estructura de oportunidades del momento porque, sobre proporcionar la solución óptima en la economía de la seguridad para unos países arruinados por la guerra, permitía además diluir en el seno de la organización atlántica los problemas y reticencias que lógicamente producirían los nuevos desequilibrios de poder militar entre los países europeos y a la larga abordar el problema de la normalización política, económica y militar de la nueva Alemania democrática. La OTAN, en efecto, 
reforzará en los años inmediatos, ante las nuevas circunstancias de la guerra fría (la bomba atómica soviética, el triunfo de los comunistas en China, la guerra de Corea) el polo defensivo atlántico, en detrimento del europeo del Pacto de Bruselas, hasta diluir sus incipientes estructuras militares en las del Comité de defensa atlántica.

Que se trata, sin embargo, de un factor condicionante decisivo de la política europea hasta nuestros días lo expresan las tentativas ulteriores de constituir un sistema de defensa propiamente europeo como eje vertebral, al lado del proyecto de una economía unida, de una política decidida de integración europea y el desencadenamiento, al hilo de estos proyectos, de las diferentes percepciones existentes entre los países interesados sobre el alcance real de esa política.

Por centrarnos sólo en los países más representativos, Inglaterra se encontraba por su geografía, su tradición política nacional y sus experiencias históricas recientes más anclada en el mundo atlántico que en el europeo. Churchill había expuesto claramente en 1948, en la conferencia nacional de su partido, los «tres círculos» prioritarios de la política inglesa: la Commonwealth, el mundo anglosajón, con los EE.UU como centro, y la Europa unida, y en lo relativo de ésta, con una visión más económica que política, cuyo horizonte final sería el de constituir un amplio territorio de libre mercado más que el de una unión continental que incluyese instituciones propias y políticas comunes de todo tipo ${ }^{23}$. En las circunstancias políticas europeas del momento, la alineación estrecha con los EE.UU. significaba además un factor multiplicador de su influencia en Europa y en el mundo, el fundamento mismo de su poder.

Por el contrario, exactamente eso mismo es lo que significaba Europa, la proyectada Europa unida, para Francia. Contando de antemano con la complicidad involuntaria del recogimiento inglés al respecto, con la rehabilitación de su papel internacional al ser admitida finalmente, como uno de los cuatro grandes, en los acuerdos de paz y en el reparto de Alemania, contando con la situación práctica de tutela internacional de la parte occidental de este último país: la llamada Alemania Federal desde 1950, Francia pasaba a ser el referente central de la nueva situación del occidente continental. Como los EE.UU para Inglaterra, la Europa unida sería para Francia el eco reverberante de su potencia nacional. Un efecto colateral importante de esta perspectiva política sería el de solucionar el contencioso con su gran enemigo histórico, Alemania, en un marco de colaboración intereuropea y bajo disposiciones de integración, que, dada la situación tutelada de la Alemania del momento, jugarían en contra de un renacimiento unilateral de su poder. 


\section{La construcción europea, en la perspectiva del siglo XX}

Los trazos hipotéticos de esta perspectiva adquirieron un relieve inesperado cuando en 1950 el entonces Secretario de Estado norteamericano, Dean Acheson, propuso a los socios de la Alianza Atlántica el rearme alemán a fin de reforzar el flanco oriental del mundo libre, si bien, precisando, en el marco de un ejército europeo integrado. En este contexto nació poco después, a iniciativa de Francia, el proyecto de Comunidad Europea de Defensa (CED), en torno al que se van a desencadenar las diferencias entre Inglaterra, alineada a la proposición norteamericana, que en síntesis propugnaba la organización de ese eje militar europeo dentro del sistema de defensa atlántico, y Francia, que lo veía más bien como uno de los pilares de una política más amplia de integración europea, en la que se diluyese el problema de la normalización internacional de la nueva Alemania Federal. Las discusiones, desde estas bases, del tratado de defensa no van a satisfacer totalmente las pretensiones francesas, y no solo por la oposición inglesa a cualquier pretensión de incorporar objetivos extraños a los desarrollados en el seno de la Alianza Atlántica, es decir, los objetivos que apuntaban a una integración política, como los de un presupuesto y de un programa comunes de armamentos y equipamientos europeos y los de unas instituciones específicamente europeas de defensa, sino también por la resistencia de los países del Benelux a conceder a éstas últimas excesiva autonomía y resucitar por esta vía los viejos demonios del «equilibrio europeo». De esta forma, aunque el tratado fue concluido, ni Inglaterra adoptó el compromiso de asumirlo ni tampoco, finalmente, tras varios años de dudas, mereció la ratificación del propio Parlamento del país promotor, Francia, en un momento, 1954, en que había iniciado ya su propia política de investigación nuclear.

Este fracaso arrastró el de otro proyecto de integración propuesto en el seno del Consejo de Europa: la Comunidad política europea (CPE) con el objetivo de coordinar los activos políticos del propio Consejo y las políticas sectoriales llevadas a cabo por el resto de las instituciones europeas entonces existentes (la CECA, la prevista CED) así como el de actuar de puente entre los países miembros de éstas instituciones y los del resto de integrantes del Consejo. Como contrapartida, tanto Francia como Inglaterra, desde sus respectivas posiciones, vieron en ello la posibilidad de apuntarse un tanto en la disputa de la supremacía por fijar las nuevas líneas de la política europea con la reactivación del viejo Pacto de Bruselas, incorporando ahora, además, a Italia y Alemania. Así fue como se negoció la creación en 1954 de la Unión Europea Occidental (UEO), un organismo intergubernamental europeo 
en materia de defensa que, a pesar de los avances respecto a su predecesor, mantenía la dependencia anterior frente a la OTAN desde el punto de vista estrictamente militar, lo que satisfacía plenamente a Inglaterra, pero al mismo tiempo con algunas virtualidades en el control de los armamentos europeos y, muy especialmente, en la subordinación de la Alemania rearmada a un organismo europeo de defensa, antes de su incorporación al sistema atlántico, así como en la implicación más decidida de Inglaterra en órganos de colaboración entre los países del continente, lo que proporcionaba algunas compensaciones a la voluntad nacional-europeísta francesa ${ }^{24}$.

No se puede decir que este acuerdo cerrase las diferencias de base sobre el sistema de seguridad y defensa europea. En los años siguientes la permanencia del contencioso, una variante, en definitiva de las diferentes posiciones sobre la construcción europea en general, se expresó en la política nacionalista francesa del general de Gaulle, que por el paradójico efecto antes mencionado, resultaba además la de mayor énfasis europeísta. En ella se imbricó el entendimiento personal entre el general y el otro protagonista principal de la política europea del momento, el canciller alemán Konrad Adenauer, lo que llevó a desplazar el centro de la política europea, antes protagonizada por las disputas franco-británicas, hacia el eje franco-alemán; en ella se incribió el veto francés en 1963 a la solicitud de ingreso de Inglaterra en el Mercado Común tras los acuerdos de Nassau de este país con los EE.UU. por el que se integraba estrechamente en el sistema de disuasión nuclear norteamericano. En ella, en fin, se insertará la salida de Francia del mando militar integrado de la OTAN en 1966 por diferencias en torno a la nueva política atlántica de respuesta graduada y de armamento nuclear. En resumen, bajo estos perfiles quedaban delineadas en el campo que nos ocupa las posiciones de los distintos actores europeos. $\mathrm{Y}$ lo que lo hace particularmente interesante es que el mismo orden de factores va a intervenir en la fase más reciente de la reflexión europea sobre su política de defensa y seguridad, abierta por el tratado de Maastricht, como más adelante veremos.

\section{La reconstrucción y la reorganización económica continental}

No menos urgente a los ojos de los políticos de ambos lados del Atlántico que la tarea de organizar la seguridad europea frente a la amenaza soviética fue la de emprender la reconstitución económica del continente. Ya desde los últimos años de la guerra los créditos norteamericanos orientados a sostener el esfuerzo militar frente al 


\section{La construcción europea, en la perspectiva del siglo XX}

nazismo llegaron abundantemente a los países aliados de Europa, especialmente a Inglaterra y Unión Soviética. Pero su interrupción en 1945 en respuesta a la actitud expansionista soviética sobre el Este europeo, precisamente en un momento en que se sufrían más agudamente los desastres de las últimas etapas de la guerra, dejaba a los europeos a una situación dramática, proclive a cualquier aventura política. El cambio de política llegará sólo dos años más tarde, urgido, otra vez, por las nuevas circunstancias que imponían sobre el tablero europeo las etapas preliminares de la guerra fría. En 1947 el presidente Truman primero y después su Secretario de Estado, George Marshall lanzaron la idea de un plan de ayuda norteamericana para la reconstrucción material y económica de los países europeos, incluidos los del Este siempre y cuando renunciasen a orientar su economía hacia la Unión Soviética. El plan daba por descontado además que los créditos sólo llegarían a ser votados por el Congreso norteamericano a partir de un acuerdo europeo para crear instituciones comunes capaces de aplicar coordinadamente, a través de una política de convertibilidad monetaria y de librecambio, la cooperación económica prevista. El rechazo del plan por parte de la Unión Soviética y de los países bajo su influencia aceleró el proceso de coordinación entre los países occidentales interesados y en la llamada Conferencia de los dieciseis, celebrada en París a partir de julio de ese año quedaron perfilados, no sin las habituales divergencias franco-británicas, las principales estructuras de gestión del plan, que cristalizarán al año siguiente en el primer amplio organismo de colaboración económica europea de la postguerra: la Organización Europea de Cooperación Económica (OECE). Un organismo, preciso es subrayarlo, de cooperación y no de integración, más basculado, pues, sobre la concepción británica de Europa que sobre la francesa ${ }^{25}$, con un mecanismo intergubernamental de toma de decisiones confiado al órgano central, el Consejo de Ministros, con un comité ejecutivo y un secretariado general y numerosos comités técnicos sectoriales ${ }^{26}$.

No obstante estas limitaciones, no es posible desconocer las virtualidades positivas del nuevo organismo, que fueron en síntesis tres: un instrumento de coordinación y eficacia en la aplicación de las ayudas, un primer avance en la liberalización de los intercambios financieros y comerciales en Europa, que pronto se completarían con la creación de la Unión europea de pagos (1950), y destacadamente una forma, como ha dicho uno de los observadores de esta experiencia europea, de «amarrar sólidamente el nuevo Estado alemán a Occidente» ${ }^{27}$.

Fue, sin duda, un pequeño avance en la resolución de los numerosos asuntos problemáticos que lastraban la inestable situación de la Europa 


\section{Francisco Villacorta Baños}

de postguerra. Uno de los más importantes, aparcado también en los acuerdos de la OECE, concernía al control de los recursos económicos del Ruhr, el verdadero corazón industrial de Europa y base tradicional del poderío económico germánico, que los gobiernos franceses consideraban una cuestión estratégica, esencial para el resurgir de su economía y para su seguridad nacional. El asunto estuvo presente en todas las reuniones multipartitas de los acuerdos de paz celebradas en aquellos años. Desde 1948 la cuestión fue confiada a una comisión internacional integrada por los tres grandes occidentales y los países del Benelux, la Autoridad internacional del Ruhr (AIR), con el encargo de gestionar el acceso a los recursos carboníferos de la zona. Aunque bajo circunstancias ciertamente nuevas en este momento, el objetivo último a que apuntaba: la descartelización y liberalización de las producciones estratégicas -el carbón y el acero-, el libre acceso, controlado internacionalmente, a las grandes rutas fluviales centroeuropeas, no resultaban totalmente novedosas en el panorama de la colaboración intereuropea en la zona, según vimos más atrás acerca de la actitud de ciertos círculos económicos del «triángulo renano», encabezados por Emile Mayrisch, en la primera postguerra.

De forma que en absoluto se puede considerar una novedad la iniciativa emprendida el 9 de mayo de 1950 por el entonces ministro francés de Asuntos Exteriores, Robert Schuman, con el apoyo técnico en la sombra del Comisario del Plan de modernización y equipamiento, Jean Monnet, de proponer un plan de efectos a la vez económicos y políticos, un plan europeo, pero con una incidencia particular en Alemania. Los económicos, emplazar el conjunto de la producción europea de carbón y acero bajo una Alta Autoridad común que rigiese las modalidades de la producción y la concurrencia. Los políticos, avanzar por ese camino hacia una federación europea y enmarcar en ella una reconciliación histórica con Alemania. La aceptación inmediata por parte del canciller Adenauer, que vió en la iniciativa una oportunidad inmejorable de evitar el control de países extranjeros (vía la AIR) sobre los recursos alemanes, y el efecto de arrastre que eso tuvo sobre los otros países del entorno (Bélgica, Holanda, Luxemburgo e Italia, en este último con un europeísta convencido como De Gasperi al frente), abrieron el camino a una negociación, que culminó al año siguiente con la creación de la Comunidad Europa del Carbón y del Acero (CECA), la primera institución del tronco específicamente europeo, la primera, por lo demás, acogida al «método comunitario» de pequeños pasos y de acuerdos de índole técnica, que tan eficaces efectos habrá de tener en los años inmediatos en el avance de la integración europea. 
Esta entidad tuvo además el mérito de poner en franquicia el esquema institucional, que se repetirá, con variaciones y añadidos, en los organismos europeos posteriores hasta el momento presente: una Alta Autoridad ejecutiva, un Consejo de Ministros, una Asamblea o Comité consultivo y un Tribunal de apelación y de conflictos frente a las decisiones de los órganos comunitarios.

Tal vez sea éste el momento de ponderar además, sobre los fríos factores del interés y la diplomacia, la importancia de los hombres -los citados estarán para siempre en el panteón de los «padres de Europa»- en la genealogía de la unión. Hombres, tres de ellos, de frontera: el loreno, (Schuman) el renano (Adenauer) y el trentino (De Gasperi), sensibles por ello -se ha dicho- a una historia hecha de guerras e invasiones, con una percepción particularmente aguda de la relatividad y de la fragilidad de las fronteras ${ }^{28}$, supieron extraer de esa experiencia un proyecto general de paz y de colaboración para el porvenir de Europa. Hombre, el tercero (Monnet), discreto, tenaz y trabajador como puede serlo un prestigioso servidor de la Administración francesa, curtido en la técnica de las negociaciones comerciales, tuvo la virtud de percatarse de que las estadísticas son un argumento de peso cuando se confrontan -o cuando flaquean- las convicciones políticas. Y que es posible llegar a puerto con ellas por entre los escollos de los principios y las reticencias nacionales.

Recojamos a continuación algunos otros nombres, tal vez menos conocidos pero sin duda también esenciales en el camino emprendido: los del belga Paul-Henri Spaak, el luxemburgués Joseph Bech, el holandés Johan Willem Beyen, el alemán Walter Hallstein, el francés Antoine Pinay, el italiano Gaetano Martino. Todos ellos han sido también protagonistas maduros de los dramáticos acontecimientos vividos por Europa en las últimas décadas. Todos están presentes en San Domenico de Taornina, en Sicilia, en junio de 1955, cuando, en el marco de una de las reuniones del Consejo de Ministros de la CECA, se lanza la idea de una unión económica europea, un Mercado Común, y de un acuerdo político sobre el nuevo sector de la energía atómica. Detrás de ellos está de nuevo Monnet, dimisionario de su cargo de Alto Comisario de la CECA para consagrarse completamente a la tarea de la construcción europea al frente del Comité de Acción para los Estados Unidos de Europa ${ }^{29}$.

Las negociaciones fueron laboriosas y estuvieron marcadas por las distintas sensibilidades acerca del proyecto europeísta emprendido y por las diferentes culturas políticas nacionales: el librecambismo matizado de los países del Benelux y especialmente de Alemania, muy 
condicionada por su valedor americano y deseosa de dar facilidades en Europa a su de nuevo pujante industria, la tradicional posición intervencionista francesa, partidaria de consolidar políticas comunes en todos los sectores y, en concreto, particularmente sensible al establecimiento de una política agraria común, gestionadas todas ellas por instituciones europeas particulares. Mención particular merece la actitud de Inglaterra, país observador en las sesiones negociadoras, pero actuando desde fuera frente a las orientaciones que se allí se emprendían. Como observador su actitud fue más bien pasiva -lo apuntaba irónicamente el negociador citado en el frontispicio de estas páginaspero desde el seno de la OECE emprendió una campaña para organizar en el marco general de la Europa occidental un espacio económico de libre cambio, para disolver en él, en definitiva, el proyecto de mercado común de los Cinco, según se ha dicho, como «un terrón de azúcar en una taza de té» ${ }^{30}$. Sus maniobras no tuvieron los efectos perseguidos y fruto de esta dinámica fue la creación a comienzos de 1960, tras la ratificación del acuerdo alcanzado entre los Cinco, de una entidad reguladora del libre comercio entre algunos de los países europeos -además de la propia Gran Bretaña, Suecia, Noruega, Dinamarca, Austria, Suiza y Portugal- no incorporados al Mercado Común. Fue la Asociación Europea de Libre Cambio (EFTA, AELE).

Las negociaciones de los Cinco alcanzaron, en efecto, un resultado muy positivo y con mayor inclinación hacia la posición francesa de lo que, a juzgar por estas dificultades, se hubiera podido imaginar. Los acuerdos, ratificados por ese núcleo inicial de la nueva Europa, preveían, por una parte, un mercado económico común, con supresión paulatina de las tarifas aduaneras entre los Estados miembros, la adopción de políticas comunes en sectores esenciales de la economía comunitaria, en especial en el agrícola, y el funcionamiento integrado de ese espacio económico frente a países externos; por otra parte, una organización concertada de la investigación, producción y mercado de la nueva energía atómica. Tales fueron los principios más básicos de los tratados firmados Roma en 1957, constitutivos de la Comunidad Económica Europea (CEE) y de la Comunidad Europea de la Energía Atómica (EURATON).

En la década siguiente la empresa europeísta fue asentándose sobre un número creciente de funcionarios y técnicos de los países miembros, consagrados a la plasmación jurídica y técnica de los objetivos económicos previstos (desmantelamiento aduanero, políticas comunes, acuerdos comerciales) y sobre una cada vez más afinada decantación de los principios políticos del funcionamiento institucional comunitario. No siempre fueron etapas fáciles en el camino emprendido. Sin embargo, 


\section{La construcción europea, en la perspectiva del siglo XX}

al concluir la década la política económica comunitaria se había asentado sólidamente, amparada en una etapa de crecimiento sostenido, y sus mecanismos de actuación habían logrado superar con éxito las múltiples pruebas sufridas.

No fue esta última una de las tareas menores: afrontar los desajustes en el funcionamiento de las instituciones europeas hasta llegar a la integración institucional de 1965, decantar el proceso siempre extraordinariamente complejo de toma de decisiones, financiar las políticas comunes. Todo ello condujo a numerosos momentos difíciles, en especial el que se inició en 1965 a propósito de las diferencias sobre la adopción de la política agraria común (PAC) y que llevó a Francia a la política de retraimiento durante algunos meses de las instituciones comunitarias -la política de silla vacía- hasta lograr el reforzamiento del principio intergubernamental, es decir, de unanimidad en las decisiones, por el acuerdo de Luxemburgo de 1966; un repliegue sobre el principio nacional que, sin embargo, hizo posible el asentamiento del marco de actuación comunitario capaz de hacer frente a las etapas ulteriores de incorporación de nuevos miembros: las de Inglaterra, Irlanda y Dinamarca en 1972, la de Grecia en 1981 y las de España y Portugal en 1986.

De cara al exterior el Mercado Común tuvo que hacer frente a las ofensivas librecambistas encabezadas por el eje EE.UU-Inglaterra en el seno de las instituciones económicas internacionales: la ronda Kennedy en los años sesenta, que permitió una considerable rebaja de los derechos aduaneros para sus intercambios comerciales; la ronda Uruguay en los 80 a propósito de la política agrícola comunitaria.

\section{La reconciliación europea. El nuevo estatuto de convivencia política continental}

La economía ha sido la coartada perfecta que ha hecho avanzar la construcción europea, ha significado el gran pretexto que ha permitido construir una nueva arquitectura supranacional partiendo de la competición entre las naciones, proyectarse hacia una identidad común partiendo de lo heterogéneo culturalmente; ha sido sobre todo la coartada perfecta de lo político, -de lo político en el sentido más general y noble: lo que atañe al orden racional y pacífico de la comunidad, en este caso continental- que ha sido el verdadero motor, su fundamento político y moral, de la tarea de la construcción europea. La empresa europeísta no se entendería, en efecto, -y no sólo en sus primeras etapas, aunque sí destacadamente en ellas, que podríamos concretar en las dos postguerras- sin esa dimensión moral de la política, que 


\section{Francisco Villacorta Baños}

es la paz. «La identidad europea -ha escrito al respecto René Giraultestá ligada a la voluntad de fundar las relaciones internacionales y las relaciones intereuropeas sobre el derecho de arbitraje» ${ }^{31}$. Pero ciertamente tampoco sería posible entenderla sin el juego laberíntico de tensiones que generaban las viejas relaciones de poder entre los Estados nacionales Puesto que las circunstancias -la fuerza de las inercias nacionalistas, las apariencias del interés corporativizado- no permitían construir Europa de esa manera directa que exigía una política de paz, se ha comenzado por derribar las fronteras comerciales y financieras, establecer políticas económicas comunes, actuar como unidad económica frente a países terceros, etc., que se legitimaban a corto plazo por los beneficios inmediatos que producían, pero sobre cuyas virtualidades a largo plazo no cabe ningún malentendido: la suma total de estas cuentas ha sido un nuevo orden político europeo, que es posible dibujar bajo dos perspectivas diferentes: el convencimiento, si se quiere expresarlo con este giro economicista, de que la paz era el mejor de los negocios y el hecho de que la toma de decisiones respecto a cuestiones económicas concretas de índole industrial, agrícola, comercial o financiera terminaba por afectar a cuotas crecientes de la soberanía de los Estados integrantes. Este cruce intrincado de objetivos e intereses, explícitos o implícitos, es el que hace, en ocasiones, tan difícil de entender las actitudes de algunos países -pongamos el caso más destacado: Gran Bretaña- respecto al proceso europeísta. Lo que sucede a fin de cuentas es que se están sopesando diversos campo cruzados de interés, a veces contradictorios, al hacer el balance general de las cuentas. Esto es lo que se estaba produciendo en síntesis en los años cincuenta-sesenta en Europa, so capa de los acuerdos económicos, y lo que ponía a una nación como la citada, aureolada por su poder y su prestigio en los primeros años de la postguerra, en una situación tan incómoda conforme pasaban los años. Porque el desplazamiento a veces imperceptible del punto de mira económico al político que las nuevas instituciones europeas consagraban a su pesar significaba inevitablemente desplazar el centro de la política europea desde el eje atlántico, en el que Gran Bretaña había gozado de un lugar privilegiado, antaño por su propio poder y hogaño por sus particulares lazos con los EE.UU, hacia el eje continental en el que el vértice Francia-Alemania comenzaban a ocupar un nuevo y sólido centro de gravedad. Pero hablar del vértice Francia-Alemania implica esencialmente entrar en una nueva dimensión de la política europea, que no es ya solo la de los intereses nacionales y económicos, sino también la de las identidades y las representaciones colectivas, que se han 
interpuesto históricamente entre todos los países europeos y de forma especialmente aguda entre los dos mencionados.

Así pues, este nuevo enfoque político de la construcción europea exige centrar la atención sobre dos cuestiones de suma importancia. La primera se refiere al acercamiento y reconciliación entre Francia y Alemania, cuestión $-\mathrm{y}$ no es posible engañarse al respecto- de una complejidad histórica y política difícilmente evaluable en sus justos términos a partir de las categorías de relación entre países europeos hoy día vigentes y que efectivamente resultará de una importancia excepcional en la empresa de integración europea ${ }^{32}$. La segunda tiene que ver con el establecimiento de un neo-equilibrio europeo, cuyo principal logro puede vincularse a la obtención de un particular estatuto de sobrerepresentación nacional de los pequeños países dentro de las nuevas instituciones europeas, en detrimento de los estrictos criterios demográficos y económicos.

Respecto a la primer cuestión, las dificultades no procedían sólo de una memoria histórica de enfrentamientos bélicos entre ambos países. La reconciliación, para ser real y duradera, debía hacerse a partir de algunos principios políticos y de algunos valores sociales y culturales compartidos, hondamente arraigados y no sólo aceptados como una más de las condiciones del armisticio. Pero tal exigencia topaba en su camino con otra memoria más profunda aún, construida no tanto a partir de acontecimientos como de sentimientos de interés y de identidad nacionales. Se trataba en concreto de la muy diversa percepción, condicionada por sus respectivas tradiciones culturales, que franceses y alemanes tenían de la nación y de las relaciones, bajo el principio del interés nacional, entre individuo y Estado: en el primer caso, el de la construcción jacobina de la ciudadanía nacional democrática; en el segundo, el del servicio a un absorbente Estado Nacional. Detrás de tales percepciones latía una tradición que había hecho del Estado Nacional y de la diferenciación respecto a las influencias culturales racionalistas de origen francés el núcleo esencial de la identidad cultural alemana. Como ha puesto de relieve N. Elías, tales contraposiciones se plasmaban arquetípicamente en la oposición entre el concepto de «civilisation», es decir, el conjunto de hechos políticos, económicos, religiosos, técnicos, morales y sociales de una comunidad, y el de «kultur», restringido más bien a los naturaleza espiritural, artística y religiosa; una diferenciación fundante de la identidad nacional que comenzó a establecerse desde el siglo XVIII y se reforzó a comienzos del XIX en las batallas ideológicas frente a la dominación napoleónica ${ }^{33}$. 


\section{Francisco Villacorta Baños}

En la coyuntura concreta de la segunda postguerra la política de reconciliación suponía romper radicalmente la inercia de una situación postbélica, en la que Alemania permanecía en múltiples aspectos bajo un estatuto de tutela internacional. Así, no puede extrañar que las iniciativas correspondiesen a Francia, en parte por la posición privilegiada que eso le proporcionaba, en parte por el efecto, antes mencionado, de proyectar sobre los nuevos planes europeos las mayores esperanzas de su propio renacimiento nacional. En todos los proyectos de carácter europeísta avanzados en aquellos años por este país latía como fondo común el intento de diluir el «problema alemán» en un gran «recipiente» europeo, lo que no dejaba de traslucir obviamente la finalidad de neutralizar en nuevas estructuras de gestión económica y política cualquier peligro de renacimiento de su poderío nacional. Así sucedió en el proyecto de Consejo de Europa, avanzado por el ministro de Exteriores francés Georges Bidault en la sesión del Consejo consultivo de la Unión Occidental celebrada en La Haya el 19 de julio de 1948, con la finalidad de desarrollar los objetivos políticos marcados en el pacto de Bruselas. En la aún incierta perspectiva europeísta de aquellos años se buscaba la creación de un foro de países europeos libres, capaces de aportar ideas para la tarea de unión que se anunciaba y para el arreglo pacífico y permanente del problema alemán. No se trataba, a decir verdad, de ninguna idea original puesto que había sido la cuestión central del magno congreso europeísta celebrado en La Haya en mayo de ese año. Pero sí indicaba el reencaucamiento nacional de las iniciativas federalistas, mucho más radicales en sus objetivos. La Asamblea del Consejo de Europa constituida, en efecto, al año siguiente quedó finalmente reducida a unas funciones meramente formales de consejo, debate y salvaguarda de los derechos fundamentales del hombre y de los principios de la democracia política, tarea importante, sin duda, que ha continuado ejerciendo hasta el día de hoy, pero sin capacidad efectiva de carácter ejecutivo, legislativo o judicial, y con el contrapeso de un Consejo de Ministros de funcionamiento intergubernamental.

Aquella misma finalidad explícita de organizar la reconciliación franco-alemana se encontraba también en los proyectos que se sucedieron a continuación, como las frustradas Asociación de Defensa Europea y Comunidad Política Europea, el plan Fouchet o el pacto bilateral franco-alemán de 1963.

Para Alemania, por otra parte, estas mismas iniciativas de integración significaron el medio idóneo para normalizar relativamente las relaciones con sus vecinos occidentales, para garantizar su integridad 


\section{La construcción europea, en la perspectiva del siglo XX}

nacional frente al poderoso imperio oriental y para reivindicarse como nación nueva a partir de la constitución de la República Federal; en definitiva, para reivindicarse contra sí misma, contra su identidad y su historia de casi un siglo y contra la tentación de reemprender algún día la senda abandonada. Durante muchos años, Alemania fue la nación más europeísta del continente, la abanderada de la Europa federal, tradición que, en apariencia, apenas se ha modificado hasta el momento presente, aunque las razones hayan cambiado tanto desde la apertura política del canciller Brandt hacia el este y, especialmente, desde la unificación que apenas pueda ser hoy en día reconocida en aquel europeísmo inicial ${ }^{34}$.

No es posible dejar de subrayar de nuevo aquí el peso de los factores personales. Desde la mano tendida por Schuman en $1950^{35}$ el eje Francia-Alemania ha sido el auténtico motor de la construcción europea y su velocidad ha sido tanto más rápida cuanto mejor ha sido el entendimiento personal entre los dirigentes de ambos países. Adenauer y de Gaulle marcaron el hito más difícil de este reencuentro nacional: el que cerraba relativamente las heridas de la guerra. Lo quisieron convertir en guía de la política europea en el llamado plan Fouchet de confederación europea de 1961, del que hablaremos más adelante, y al fracasar, acudieron al acuerdo histórico de reconciliación francoalemana de 1963. Salvado el escollo de los desencuentros ulteriores a propósito de la política agraria, con Schmidt/Giscard D'Estaing y con Kohl/Mitterrand la velocidad europeísta volvió a recuperar empuje, acompañada inseparablemente de un nuevo impulso en la política de reconciliación, al menos hasta el escollo de la reunificación alemana después de 1989.

Pero junto a la reconciliación de estos dos países, el nuevo orden político europeo no podría haber avanzado sin la contribución decisiva de los pequeños países europeos: Bélgica, Holanda y Luxemburgo. A su presencia entusiasta en el proyecto europeo desde primera hora se debe el triunfo de una concepción radical del principio democrático entre naciones, que privilegia el respeto y la representación de lo minoritario sobre el peso ciego de lo cuantitativo. Ellos abanderaron la oposición a conferir a las nuevas instituciones europeas una capacidad de gestión autónoma que pudiese derivar en nuevas formas de supremacía por parte de los grandes países del continente. Ellos han sido los mayores defensores del principio intergubernamental que ha regido rigurosamente durante mucho tiempo la toma de decisiones en las entidades europeas, incluido el derecho de veto. Por encima del principio de eficacia, que ha sido con frecuencia el argumento aducido 
por parte de los federalistas europeos en contra estos procedimientos de actuación institucional, con ellos ha prevalecido la norma superior de un nuevo equilibrio europeo por primera vez verdaderamente democrático, es decir, aceptable para las minorías, hasta tal punto la historia de los poderes nacionales en el continente ha estado ligada a una historia interminable de agresiones hacia los pequeños países. Tal vez ningún episodio resulte más significativo de la contribución de estos países a la marcha de las instituciones europeas que el ocurrido en torno al proyecto Fouchet, conocido por el nombre del presidente de la comisión de estudios que lo elaboró a partir de 1961. Se trataba, en síntesis, de un, en apariencia, ambicioso proyecto para Europa que comprendía, además del dominio económico ya en marcha, los de la seguridad y defensa común, los de la política extranjera y los de la ciencia y la cultura, aunque acogido en su conjunto al principio confederal gaullista de la «Europa de las Patrias». Pues bien, la empecinada oposición, a pesar de las múltiples presiones, de Bélgica y, muy particularmente, de Holanda, que creían ver en estos planes un repliegue sobre el principio nacional, con el consiguiente peligro futuro de dominación de los poderes francés y alemán sobre el continente, hizo naufragar definitivamente el proyecto $^{36}$.

\section{Las cuestiones institucionales Las instituciones europeas}

Una de las alegaciones tradicionales más tópicas de las actitudes antieuropeístas ha sido la de oponerse a la burocracia «de Bruselas», lo que parece confirmar que en todos los fogones se cuece ese mismo tipo de olla podrida que, referida a «Madrid», resulta tan habitual en la cocina política española. Dejando aparte las justificables críticas a la hipertrofia de los mecanismos procedimentales, comunes a toda burocracia, que con tanta frecuencia se entremezclan interesadamente en aquel concepto, por burocracia de Bruselas habría que entender, en un sentido más riguroso, el conjunto de mecanismos intergubernamentales, procedimientos de cooperación y políticas integradas que los países europeos han ido plasmando en el funcionamiento de las instituciones comunes. Son, en este sentido, el resultado de múltiples compromisos entre las diversas sensibilidades confluentes en el proceso de unión y testifican de un modo por demás certero la transmutación profunda que en el curso de él ha producido el método comunitario desde los reformas técnicas, las «realizaciones concretas», la «solidaridad de hecho» que propugnaba en 1951 el preámbulo del tratado constitutivo de la CECA, hasta los compromisos políticos firmes de unión continental, 


\section{La construcción europea, en la perspectiva del siglo XX}

que era su auténtico objetivo último. Actuar -como decía el propio Monnet- no a partir de "una idea vaga», sino de «un punto preciso que arrastre todo lo demás ${ }^{37}$. Un observador privilegiado de todo el camino recorrido como el alto funcionario francés Alain Prate, lo expresa con total precisión: «ha sido un sistema institucional original el que ha permitido, gracias al método comunitario, sobrepasar las contradicciones y llegar a los grandes acuerdos sobre la agricultura, el GATT, el mercado único, los fondos estructurales, fundamento de la Comunidad actual» ${ }^{38}$.

No ha sido ciertamente una tarea fácil, porque esas contradicciones -fundamentalmente entre el modelo librecambista y el partidario de diseñar políticas comunes de todo tipo, que podemos vincular en términos generales a Gran Bretaña y Francia respectivamente- lejos de diluirse en la experiencia contrastada de los procedimientos comunitarios, han continuado bien vivas en las discusiones de la política común y hasta se han agudizado con la incorporación a la Comunidad de Inglaterra, Dinamarca y el resto de los países de la EFTA. Mirando al futuro, como luego veremos, continúan planeando como uno de los principales factores de riesgo para el futuro político comunitario en la prevista etapa de integración de nuevos países.

Dejando a un lado el Consejo de Europa, órgano de confluencia de los países europeos, pero no de la Comunidad-Unión, el esquema institucional comunitario - de cada entidad de política sectorial en principio, del conjunto integrado de instituciones desde 1965- comprendía una alta autoridad ejecutiva, responsable ante un Consejo de Ministros y ante una Asamblea representativa, y un Tribunal de Justicia. Un Comité económico y social y un Banco Europeo de Inversiones completaban, en un nivel más bajo, el cuadro institucional originario desde 1958. Pero bajo esta homogeneidad aparente los cambios producidos en el funcionamiento interno y en el equilibrio institucional han sido considerables en las sucesivas etapas del proceso europeo. Mientras que la Alta Autoridad de la CECA gozaba de un poder decisivo en la política comunitaria de su campo sectorial específico, y debía asentarse en principio como el embrión de un futuro gobierno europeo, tal poder fue pasando a partir de la creación de la CEE al Consejo comunitario de Ministros, dejando a la Comisión únicamente la tarea de proponer las soluciones a los problemas planteados, ejecutar lo acordado y gestionar el conjunto de las políticas comunes. Aunque la regla de oro de los acuerdos del órgano ejecutivo, el Consejo, no fue inicialmente, como lo será a partir de 1965, el principio de unanimidad y el derecho de veto, hacia esa lógica jugaba la transferencia mencionada del poder decisorio. 
En la práctica, tal sistema no siempre conseguía aparentemente un nivel óptimo de eficacia. Sus observadores privilegiados nos describen con frecuencia un conjunto inmanejable de personas (ministros, funcionarios comunitarios, grupos de expertos) reunidos en interminables sesiones deliberantes sin lograr ponerse de acuerdo. La dinámica de la negociación hacía que el presidente de turno convocase a una reunión restringida, formada por los ministros con sus más cercanos colaboradores, lo que en conjunto componía un grupo de una cincuentena de personas. Al final, las decisiones operativas terminaban adoptándose en reuniones aún más restrictivas de los ministros en el despacho del presidente o en consultas bilaterales en los pasillos ${ }^{39}$. Lento e inmanejable desde una concepción técnica de la eficacia, poseía esta cualidad en alto grado, en cambio, en su acepción política, aquella capacidad de escuchar, hablar, acercar posiciones, humanizar los desacuerdos que el negociador español Raimundo Bassols, atribuía a los países orientales y árabes ${ }^{40}$, porque, en definitiva, como el propio J. Monnet dejó escrito, esa era la virtud del método comunitario: un sistema que funcionaba a partir de un diálogo constante entre las instituciones nacionales y las instituciones comunes ${ }^{41}$.

Es cierto que con el tiempo el cuadro institucional comunitario se ha complicado considerablemente. El abanico de competencias gestionado por la Comisión se ha diversificado considerablemente (gestión del presupuesto, negociación de acuerdos con países terceros, salvaguarda de las reglas de la competencia, reparto de fondos estructurales, gestión del mercado único, control de las ayudas públicas), aunque poniendo el tope, de cara a las previsiones de futuro, en el principio de subsidiariedad ${ }^{42}$. Igualmente, el proceso de toma de decisiones se ha aligerado en cierto modo al conceder, desde 1974, una mayor entidad institucional al Consejo Europeo y al admitir, desde Acta Única, el criterio de mayoría cualificada, aunque manteniendo la exigencia de la unanimidad para las cuestiones esenciales como la fiscalidad, la moneda, los asuntos sociales y la política extranjera y de seguridad común. Y en fin, las propias instituciones comunitarias, las originarias y las nuevas, han ido completando el círculo funcional y tutelar propio de un Estado en sentido pleno. En 1977 entró en funcionamiento el nuevo Tribunal de Cuentas, órgano técnico superior de control de los gastos comunitarios. Desde 1979 la Asamblea Parlamentaria se elige directamente con plena legitimidad democrática por los ciudadanos europeos, aunque sus capacidades legislativas continúan siendo muy limitadas. Y con posterioridad, ya en la nueva etapa económica y política abierta en 1989, han ido surgiendo, por solo mencionar las más im- 
portantes, el Fondo Europeo de Inversiones (1994), el Comité de Regiones (1994), el Defensor del Pueblo Europeo (1995) y el Barco Central Europeo (1998).

\section{España en Europa}

Calificar a España en relación al movimiento europeísta es antes de nada dejar constancia de una ausencia -marginación sería la calificación más justa- disfrazada ante el interior del país de altanería o displicencia nacionalista. Pero esta constatación, cierta en sus líneas principales, no puede inducir al error de identificarla con aislamiento intelectual o apartamiento en sentido amplio de las condiciones históricas de todo tipo a partir de las que se ha construido Europa o de las que es posible imaginarla en el futuro. Y ni siquiera con ausencia de iniciativas y movimientos de opinión internos relacionados con las etapas fundamentales de la construcción europea, aunque se mantuviesen en unos términos puramente privados o testimoniales ${ }^{43}$.

El aislamiento de España en los momentos cruciales de la reconstrucción económica de Europa y de diseño de las nuevas instituciones unitarias fue el impuesto por su régimen político. Siempre sería posible matizar históricamente las cuotas de responsabilidad que a cada país corresponden en la situación internacional de España, en verdad excepcional después del acuerdo de Postdam de 1945, a la luz de los comportamientos contemporizadores adoptados frente a las agresiones totalitarias previas al desencadenamiento de la guerra mundial. Pero eso no forma parte directa de nuestro tema de análisis, desde el que solo cabe dejar constancia de la relegación de España de las ayudas del plan Marshall, de la OECE, (al menos hasta 1959 y bajo las condiciones que analiza Lorenzo Delgado en una de las aportaciones de este monográfico) del Consejo de Europa, de la OTAN, de la CECA, de la CEEEURATON y de la EFTA. Estas últimas instituciones pertenecían ya a la etapa de normalización de las relaciones internacionales de España posterior a 1950 en plena agudización de la guerra fría, en la que los argumentos estratégicos comenzaban a pesar cada vez más sobre los puros principios políticos. La contradicción fundamental permanecía anclada, no obstante, en la naturaleza misma del régimen, en su incompatibilidad con los objetivos de paz y democracia del proyecto europeo.

Un testigo y actor privilegiado de las etapas ulteriores de la relación de España con las instituciones europeas, como es Raimundo Bassols, nos ha proporcionado un excepcional testimonio de sus vicisitudes, construido a partes iguales sobre datos bibliográficos, documentación 
de archivo y experiencias personales, centrado por igual sobre problemas técnicos y problemas políticos. Hitos fundamentales de esa trayectoria, anteriores a la apertura definitiva en 1979 de las negociaciones para el ingreso en las Comunidades, fueron la carta del ministro de Exteriores, Antonio $\mathrm{M}^{\mathrm{a}}$ Castiella, en 1962 solicitando formalmente la apertura de conversaciones con vistas a la incorporación futura de España al Mercado Común, el nombramiento en 1965 de Alberto Ullastres como representante permanente de España ante las instituciones comunitarias, quien, junto con José Luis Cerón, director general de relaciones económicas internacionales, jugó un papel decisivo en las primeras etapas de la inserción europea de España; la firma del acuerdo España-CEE de 1970, la ampliación comunitaria de 1972 y la renegociación interminable del acuerdo del 70, en cuyo proceso confluyó ya con la etapa de cumplimiento de las condiciones políticas para la homologación plena de la España europea y con su incorporación al conjunto de las instituciones políticas, económicas y defensivas del continente: el Consejo de Europa, la OTAN, las Comunidades. Proceso próximo, bien conocido, en el que hemos decidido no entrar por las razones que a continuación mencionaremos ${ }^{44}$.

En efecto, a partir de todo lo que venimos diciendo, la ecuación que más certeramente resume la actitud de España respecto a Europa es la del europeización, dando a este concepto el sentido que desde la fecha-gozne de 1898 ha venido imponiéndose en gran parte de la opinión intelectual, en alguna, al menos, de la política y en un substrato profundo de la conciencia nacional: esencialmente un procedimiento corrector de nuestra idiosincrasia castiza a través de más bienestar económico, más seguridad vital, más democracia, más educación, cultura y ciencia y una actitud más abierta y emuladora hacia todas las posibilidades de relación directa con los países vecinos; en la perspectiva, en definitiva, de sentirse otros sin dejar de afianzar las raíces en la propia tierra. La perdurabilidad de este amplio substrato europeísta del regeneracionismo en las sucesivas etapas de la política exterior española ha sido puesto de relieve con frecuencia en la investigación histórica, desde la época de la II República hasta, pasado el interregno franquista, la generación de los jóvenes políticos que en los años 80 incorporaron España a la Comunidad ${ }^{45}$. Este tipo de consideraciones es el que nos ha empujado a emplazar los estudios monográficos acerca de la España europea aquí recogidos en la perspectiva amplia de una Europa posible, que no está escrita -solamente habría que matizaren los pliegos de los tratados ni en los textos jurídicos, sino en segmentos compartidos de identidad, de cultura y de complementariedad. Desde 


\section{La construcción europea, en la perspectiva del siglo XX}

la perspectiva todavía incierta, pero ya esperanzada, de 1973, uno de los historiadores del trayecto europeísta realizado por España hasta aquel momento lo expresaba con bastante precisión: «afortunadamente -decía- los pueblos son más fuertes que los gobiernos y los regímenes. No importan las distancias constitucionales o los recelos políticos de frontera a frontera; la cuestión europea la acabarán determinando, por parte española, los millones de trabajadores y visitantes que cruzan en los dos sentidos los Pirineos, los hombres de negocios con intereses técnicos y financieros a ambos lados, los estudiosos que no pueden prescindir de la ciencia alemana o del conocimiento filosófico francés, los funcionarios que contrastan experiencias en toda Europa, los políticos que son capaces de mirar más allá de su parroquia, los clérigos que acaben por percatarse de que el concepto de una "iglesia española" es inane» ${ }^{46}$. Ahí están subrayados algunos de los motivos temáticos de los trabajos que el lector encontrará en este monográfico.

\section{Europa como posibilidad}

Puesto que desde la fecha mencionada España ha logrado efectivamente formar parte de las instituciones europeas ¿podemos concluir de ello que ese designio europeo entrevisto por tantos españoles desde finales del siglo XIX ha quedado por fin colmado? Sin duda sería aventurado afirmarlo. Más bien habría que decir que la concepción europea de España se ha acompasado a la de sus vecinos y ya no es el signo de una carencia, sino el de una posibilidad: la que comparten con todos ellos de construir una nueva entidad política llamada Europa, cuyo alcance está todavía por definir en términos precisos. Para un país como España, que ha vivido mucho más la utopía europea que su realidad institucional se trata también de asumir la dura inmersión en un proceso, que se construye ciertamente por medio de las instituciones y de los vínculos de todo tipo entre las sociedades europeas, pero que tiene mucho de incierto y problemático. Porque, en efecto, a pesar del tiempo transcurrido desde las primeras etapas de la Europa unida, a pesar de los lazos múltiples entre gobiernos, entre instituciones, entre empresarios, entre individuos, propiciados por las instituciones comunitarias -ésta es una de las conclusiones a que los historiadores llegaron en el proyecto de investigación europeo mencionado al comienzo de estas páginas- el problema de la identidad europea continúa bajo el signo interrogante ${ }^{47}$.

La constatación está hecha desde luego partiendo de un posicionamiento claramente europeísta y, por lo tanto, tal vez en exceso pe- 
simista acerca del alcance real de lo ya logrado, en exceso impaciente por alcanzar un futuro que se concibe no solo como marco institucional, sino como impregnación cultural en profundidad a partir de lo compartido por todos los países europeos. El futuro de Europa se perfila en ambas dimensiones con tantos retos como dificultades, que es lo que vamos a desarrollar someramente a continuación.

Una parte importante de la posibilidad de esa nueva Europa se juega en las apuestas institucionales emprendidas en la última década. Desde el Acta Única de 1986 y el tratado de Maastricht de 1992, con Jacques Delors a la cabeza de la Comisión, Europa ha entrado en una nueva fase de aceleración histórica, cuyos resultados están en estos momentos en pleno desarrollo: el euro, la autoridad monetaria europea, la supresión de la casi totalidad de las fronteras interiores, la nueva política de seguridad y defensa europea, como las políticas sociales, las políticas regionales. Todo parece indicar que, a pesar de las dificultades y resistencias, el campo de la economía continúa actuando, en la línea que ha sido habitual desde las primeras etapas europeas, como la punta de lanza del proceso de unión y que a corto y medio plazo será el factor de mayor impacto en la vida cotidiana de los ciudadanos europeos. El objetivo más emblemático, el euro, esperado por unos países de la Unión, temido por otros, constituye, según $\mathrm{N}$. Gnesotto, la clave del porvenir federalista europeo, ya que concentra por sí mismo los dos elementos constitutivos de la Europa política: la cesión en un punto crucial simbólico de la soberanía de las naciones y la relación con América, en la medida en que dentro del proceso de mundialización económica ello le proporcionará una creciente posibilidad de independencia respecto a la moneda americana. Ambos elementos obligarán a todo un replanteamiento de los mecanismos institucionales y políticos de relación de los Estados integrantes entre sí y con los EE.UU ${ }^{48}$. Lo que en ese proceso no está descartado en absoluto es que el tránsito en este terreno económico desde la Europa de los quince a la de los veintisiete previstos en los próximos años no conduzca, dada la dificultad para gestionar la diversidad de situaciones económicas, hacia una relajación de las políticas comunes en ese campo, con carácter general o por la vía de las adhesiones a la carta, acercando el resultado final a la concepción europea anglosajona de un gran espacio de libre cambio. La tantas veces sugerida amenaza de un núcleo duro reducido de países de avanzadilla de una auténtica Europa política ha sido la respuesta más común a ese peligro, algo más que hipotético, de disolución, vía un vasto mercado abierto, de la Unión política.

Las dificultades para la posible Europa futura resultan aún más agudas en lo referente a la política de seguridad y defensa común. 


\section{La construcción europea, en la perspectiva del siglo XX}

Y sin embargo, ahí se encuentran algunas claves esenciales del proceso comunitario. Buena parte de las iniciativas europeístas de la época gaullista partían del supuesto de que no puede haber personalidad política de Europa si Europa no tiene personalidad desde el punto de vista de la defensa ${ }^{49}$. En esta línea fueron su memorándum de 1958 proponiendo la reforma de la OTAN para crear un directorio que permitiese a París, Londres y Washsington gestionar de forma colegiada los asuntos del mundo, el plan Fouchet, tras el fracaso de la propuesta anterior, e incluso el acuerdo bilateral franco-aleman de 1963, que incluía previsiones de una defensa común, aunque los alemanes se apresurasen de inmediato a encuadrarlas en el seno de la OTAN. Hilando un poco más fino, un agudo observador actual, como el intelectual francés Regis Debray, ha percibido claramente que las posibilidades de un salto cualitativo en el sentimiento europeísta hasta la cota deseable de un federalismo más o menos estrecho -al margen las modalidades concretas de plasmación constitucional- se encuentra ligado a la aceptación por parte de las opiniones públicas europeas de una responsabilidad consecuente, específicamente europea, en su seguridad y defensa, lo que incluye la asunción de una identidad cultural europea lo suficientemente estrecha como para aceptar todas las consecuencias implícitas en esa responsabilidad hasta los límites extremos de la guerra. "No puede haber comunidad de defensa -ha escrito- sin comunidad de cultura...», porque -ha añadido gráficamente- "se crea como se lucha: con el alma y las tripas» ${ }^{50}$.

Los pasos en esta dirección han sido considerables en la última década. Una de las novedades del tratado de Maastricht fue la de sacar del olvido el proyecto, tan caro a los franceses, de poner en pie una política común de seguridad para hacer de ella el núcleo de una estructura de defensa europea futura. Este proyecto no ha pasado por el momento de sus primeras etapas. Es cierto que la iniciativa franco-alemana en 1991 tuvo el efecto de crear un cuerpo de ejército común, integrado por una división mecanizada alemana, una división blindada francesa y una brigada conjunta (el Eurocuerpo), iniciativa a la que se han unido posteriormente otros países, entre ellos España. $\mathrm{Y}$ que asimismo a partir de estas fechas es un dato jurídico de la Unión la instauración de una política extranjera y de seguridad común (PESC). Pero otra cosa es la posibilidad, ciertamente lejana, de que todo ello se convierta en una alternativa real al flanco europeo de la OTAN, en primer lugar porque en sí misma tal política solo pudo ponerse en práctica tras un cambio considerable de la tradicional reticencia francesa respecto a la OTAN, y tras el acercamiento de esta 


\section{Francisco Villacorta Baños}

organización y la UEO, que en 1984, en una declaración conjunta, reconocieron el «carácter indivisible de la seguridad en la zona del Atlántico norte ${ }^{51} \mathrm{y}$, en segundo lugar, porque ello rompería con aquella decisión asumida por los europeos desde el final de la guerra, que mencionábamos más arriba, de dejar su seguridad y defensa en manos de los americanos. Si esta decisión, no por implícita menos real, resultó tan efectiva en el pasado, ya que permitía a numerosos países hacer economía de sus responsabilidades estratégicas y operar contra la memoria histórica de las hegemonías nacionales clásicas, ese mismo tipo de factores continúa actuando en la actualidad de cara a los países candidados a la Unión -candidatos fervientes también, si es que no lo son ya, de la OTAN- en su mayoría países centroeuropeos, que consideran la presencia de unidades americanas en suelo alemán como un freno eficaz al rebrote hipotético de tendencias hegemónicas de la nueva Alemania unificada, otro de esos peligros latentes de la unión, como veremos a continuación ${ }^{52}$.

En efecto, las posibilidades y riesgos de los nuevos retos europeos resultan especialmente agudos planteados en relación a los trascendentales cambios políticos acaecidos en Europa en la última década, en particular la unificación de Alemania y la caída de los regímenes comunistas. En la nueva Alemania se concentran buena parte de los interrogantes futuros de la Unión, ya que su enorme peso económico y demográfico significa una amenaza para los equilibrios comunitarios tradicionales en varios terrenos, incluso en aquellos que podrían parecer más positivos para la causa europeísta, como puede ser el abandono relativo del procedimiento intergubernamental de toma de decisiones comunitarias a favor de otro mayoritario más o menos ponderado, que es una de las reformas institucionales más decisivas emprendidas en los últimos tiempos. Desde el Acta Única firmada en 1986, según vimos, volvió a ponerse en marcha tímidamente ese recurso, aunque manteniendo el principio intergubernamental, incluido el derecho de veto, para cuestiones de importancia estratégica. No cabe duda, en efecto, de que se trata de una reforma de considerable alcance, repetidamente solicitada por los federalistas europeos, pero que en la nueva situación lo será así siempre que funcionen adecuadamente el resto de ponderaciones y contrapesos garantes de los equilibrios entre las naciones y los espacios de la Unión, sin lo cual podría resultar potencialmente peligroso, unido al peso hegemónico alemán ya conquistado y al que puede sobrevenirle con la incorporación de los países aspirantes centroeuropeos, entre los que el peso del poderoso vecino alemán va a gravitar de forma inevitable, a pesar de sus numerosos 


\section{La construcción europea, en la perspectiva del siglo XX}

contenciosos históricos, con el peligro subsiguiente de un nuevo desequilibrio en la Unión, esta vez geopolítico: la posibilidad, en definitiva, de entrar en una nueva dinámica imperial ${ }^{53}$. En la Conferencia intergubernamental de Niza de diciembre de 2000, que consagró el nuevo escenario de poder en las instituciones europeas con la vista puesta en la futura Europa ampliada, Alemania terminó definitivamente conquistando la posición preeminente a que parecía predestinarle su peso demográfico y económico. El interrogante que ya se planteaban algunos hace años sobre si en esta nueva situación Alemania continuaba siendo el fiable socio europeo que había sido durante muchos años resulta ahora sobremanera pertinente. Y la siguiente cuestión al respecto es sobre la forma en que funcionará el complejo sistema de ingeniería institucional puesto en práctica en aquella reunión entre la atribución de votos institucionales, el umbral de la mayoría cualificada y el encumbramiento institucional alemán. Si es que finalmente son ratificadas por los Parlamentos de los países integrantes, cosa que no está garantizado si adoptamos como criterio las recientes reticencias del Parlamento Europeo al respecto.

Lo que sí resulta ya comprobado es el efecto de esta nueva situación ha tenido sobre otro de los pilares sustentantes de la Unión: el eje París-Bonn (Berlín). Es cierto que el tiempo ha disipado casi completamente la alarma inicial provocada por la unificación alemana. Francia no ha tenido otro remedio que adaptarse a la pérdida del estatuto privilegiado, cierto que ya casi puramente simbólico, que frente a su tradicional enemigo/amigo le proporcionaba el control de una parte de la vieja capital imperial, Berlín. La amistad personal Kohl/Mitterrand pudo jugar en este terreno un papel decisivo, que ya hemos subrayado en otro lugar. Pero nada garantiza que el equilibrio que paradójicamente proporcionaba a la Comunidad esta relación desigual heredada de la postguerra no se torne en desequilibrio en la etapa de normalización internacional definitiva de la potencia alemana y que las lógicas nacional y europea -lo que hemos llamado el nacional-europeísmo francés y el europeísmo nacional alemán- no se conjuguen en ambos países de manera diferente a como lo han hecho hasta ahora.

Aún hay una última consideración pertinente respecto a estas cuestiones que venimos mencionando. En la perspectiva europeísta más favorable ies posible percibir la hipotética fase federal futura de la unión como una nueva forma, más evolucionada, de conciencia nacional, como un nuevo nacionalismo, tal y como podrían sugerir las palabras del intelectual francés arriba mencionadas? La cuestión no es de ahora, puesto que ya Julien Benda en su obra mencionada de 1933 ponía 
en guardia frente a la eventualidad de que el nuevo patriotismo europeo que propugnaba reprodujese a escala más amplia el mismo modelo de cerrado nacionalismo que venía a combatir ${ }^{54}$. Aun sin un referente inmediato tan dramático como el nazismo de aquellos días, también ahora resulta pertinente la advertencia ante los retos y las dificultades que la Comunidad aborda en sus objetivos internos y en su proyección externa. Políticos, analistas, intelectuales e historiadores europeos han coincidido desde muy diversos puntos de mira en la necesidad de abordar desde los principios más generales, y no sólo desde la razón práctica, las potencialidades del proyecto europeo. En el plano político institucional: la de un nuevo proyecto colectivo de civilización, que en una dimensión supranacional nunca hasta ahora ensayada reproduzca esa «gramática política» del mundo moderno que es el contrato social y los principios políticos sobre los que se han levantado las modernas sociedades democráticas occidentales, pero bajo nuevas bases fundantes: de individualidad nacional a individualidad nacional, en las que el principio soberano ya no será único e indivisible, como lo definió Rousseau, sino múltiple y complejo, construido en las negociaciones y en la colaboración entre Estados ${ }^{55}$. En el plano internacional, partiendo de nuevo escenario abierto por el fin de la bipolarización mundial: la del establecimiento de una política extranjera y de seguridad común basada en la defensa de la paz y la democracia y en el método de cooperación antes que en los clásicos de la realpolitik; la del ejercicio de la inevitable hegemonía que proporciona al continente unido su peso económico y demográfico en favor de la difusión de los valores democráticos y sociales. Son los principios que se han querido recoger en el concepto de «benebol hegemon ${ }^{56}$.

La segunda dimensión de esta posibilidad europea que venimos desgranando continúa confiada a la multiplicación de los lazos de todo tipo entre los entes públicos y las sociedades civiles europeas, una apuesta que si hasta el momento no ha obtenido los resultados óptimos esperados, nada indica que un marco cronológico más amplio y la profundización y diversificación de las redes de intercambio ya trazadas no lo consigan, puesto que se trata en sí mismos de mecanismos de naturaleza social y cultural, incluso antropológica, proyectados en una perspectiva histórica de tiempo largo. Es más, tal perspectiva civil de la construcción europea, confiada a la construcción de un espacio público transnacional integrado por las opiniones públicas, los movimientos culturales, las relaciones institucionales públicas y privadas son el único camino para conjugar el déficit democrático de la construcción europea, tantas veces señalado en los más recientes debates sobre el presente y el futuro de la Unión ${ }^{57}$. 


\section{La construcción europea, en la perspectiva del siglo XX}

El mejor argumento europeísta en este terreno procede del conocimiento histórico que tenemos hoy ya de todo ese tejido de relaciones europeas. Lo que comenzó siendo un objetivo económico y político a contracorriente, con frecuencia, de las opiniones públicas europeas, se proyecta hoy hacia el futuro bajo su acicate -aunque no lo sea con entusiasmo en todos los países y ni siquiera con mayoría en algunosy ese cambio no puede ser explicado únicamente por los beneficios materiales producidos por el desmantelamiento de las barreras económicas y políticas sino también por el derrumbe de otros muros invisibles mucho más resistentes, levantados históricamente entre las ciudadanos europeos: los psicológicos y culturales. La ruptura del aislamiento, que no es la causa sino el medio natural de tales barreras, es lo que las instituciones europeas han promovido con tesón y las sociedades han ejercido de forma creciente a lo largo del siglo XX y con particular intensidad en el ya medio siglo de la Europa unida.

Los resultados del proyecto de investigación europeo más arriba mencionado, desarrollado entre 1989 y 1994, que tenía por objetivo el proyecto europeísta en esta perspectiva amplia que venimos tratando, muestran hasta qué punto las pistas de una identidad y de una conciencia europeas pueden ser rastreadas con éxito en los más variados puntos de observación, aunque no dejen de ser minoritarios y de presentar cierto grado de ambivalencia: pueden serlo en los contactos crecientes entre las sociedades, en los intercambios económicos, en la emigración, en el turismo, en las relaciones académicas y universitarias, en la conciencia avanzada de los intelectuales, en la difusión de los imaginarios comunes ${ }^{58}$.

Bajo esta perspectiva están seleccionados los trabajos referidos a España aquí reunidos. Que la categoría «europeización» es uno de las más constantes en el debate intelectual español desde que a finales del siglo XIX le diera estado público Joaquín Costa apenas merece ser discutido. Que Europa/ciencia, Europa/civilización, Europa/entidad moral, jurídica y política sea una línea ininterrumpida de reflexión del más emblemático pensador español de la primera mitad del siglo, como es Ortega y Gasset, resulta, sin duda, un hecho sobremanera significativo que trasciende los límites de una biografía individual para insertarse en una biografía moral colectiva ${ }^{59}$. Tal vez se podría decir que, como ha sucedido en Alemania, Europa ha significado para España la posibilidad de ser otra cosa sin abdicar obviamente del propio sentimiento nacional, y hasta reforzándolo, de insertar -como diría el Unamuno de final del XIX, el de En torno al casticismo-- la personalidad castiza en lo universal. Sin pretender una visión sistemática de tales 
perspectivas, aquí se recogen algunos de los hilos particulares que comienzan a formar desde España la urdimbre del tejido de relaciones europeas: las juntas de pensiones, el turismo, la emigración, la participación en las nuevas instituciones. Obviamente sin una conciencia precisa en aquel momento del plano europeo específico -la Europa substantiva- en que terminarán confluyendo, pero tal vez esa inconsciencia, ese curso imprevisible de los lazos y las relaciones en todos los niveles sean los que, con la ayuda del tiempo, permitan en el futuro a los ciudadanos franceses, alemanes, españoles, italianos, etc., despertarse ciudadanos europeos sin que tal hecho implique un conflicto de identidades.

\section{Notas}

1 Duroselle, Jean-Baptiste (1965): L'idée d'Europe dans l'histoire. Paris, Denoël, p. 316 .

2 Rougemont, Denis de (1994): Oevres complètes, III: Ecrits sur l'Europe, vol. I: 1947-1961. Paris, Edit. De La Différence, p. 85. Citado por RÉAU, Elisabeth du (1996): L'idée d'Europe au XXe siècle. Des mythes aux réalités. Bruxelles, Ed. Complexe, p. 189.

3 Esta orientación presenta la obra de FERRY, J.-M. y THIBAUD, P. (1992): Discussion sur l'Europe. Paris, Calmann-Lévy.

4 Una interesante visión de conjunto, Duverger, M. (1995): L'Europe dans tous ses États. Paris, Puf.

5 Recogido por RÉAU, E., obr. cit., p. 6.

6 Estas páginas, más amplias de lo que suele ser habitual en la presentación de un tema monográfico, intentan suplir otros trabajos previstos en el mismo, relativos a este pilar -el europeo- de los dos -el otro, el español- sobre los que estaba planeado, y cuyos autores previstos no supieron cumplir con los compromisos adquiridos.

7 La reflexión europea de Ortega y Gasset es constante a lo largo de su vida y obra. Recopiló en cierta manera sus puntos de vista en la conferencia De Europa Meditatio Quaedam, pronunciada en la Universidad Libre de Berlín en 1951, después recogida en el libro Meditación de Europa. Madrid, 1960

8 Antecedentes en RÉAU, obr. cit., pp. 38-41. En esta obra se documentan, por otra parte, un buen número de los datos del europeísmo inicial que seguirán a continuación.

9 Al respecto, CARRERAS ARES, J. J.: «La idea d'Europa en l'època d'entreguerres», en Nosaltres els europeus, A. SAN MARTín, ed., (1992). València. Ajuntament de Gandia-Universitat de València.

10 Ver Mayer, Arno J. (1959): Political origins of the new diplomacy, 1917-1918. Newttaven, Yale Univ. Press.

11 Obviamente frente a hipotéticos peligros de orientalización europea, soviética o asiática, CARRERAS ARES, J. J.: art. cit., pp. 137-138.

12 Un amplio estudio de esta y otras iniciativas, en Bock, M., MeYer-KalkUS, R. y TREBITSCH, M. (1993): Entre Locarno et Vichy. Les relations culturelles francoallemandes pendant les années trente. Paris, CNRS, 1993, 2 vols. 


\section{La construcción europea, en la perspectiva del siglo XX}

13 Hijo de padre austro-húngaro y de madre japonesa, las vicisitudes nacionales centroeuropeas le hicieron pasar sucesivamente por las nacionalidades austríaca, checa y francesa.

14 Resúmenes de las iniciativas pan-europeas en BosSUAT, G.: Les fondateurs de l'Europe. Paris, Belin, 1994, pp. 26-31 y RÉAU, E. de: obr. cit., pp.81-83.

15 Les cercles économiques et l'Europe au XXe siècle, Recueil de textes réunis à l'iniciative de M. DEMOULIN et É. Bussière.......Paris, 1992, citado por BossuAT, G., Les fondateurs..., p. 48-49.

16 En el artículo «La Crise de l'Esprit», publicado en abril de 1919 en la revista L'Athenaeum, en RÉAU, obr. cit., p. 71.

17 Citado por RÉAU, E. de, obr. cit., p. 94.

18 Un pedagógico resumen de las actitudes al respecto en DUROSELLE, J.-B. (1990): Historia de los Europeos. Madrid, Aguilar, pp. 357-360. Sobre España, MENCHEN BARRIOS, M. T.: "La actitud de España ante el Memorándum Briand (1929-1931)», Revista de Estudios Internacionales, 6, 2, abril-junio 1985, pp. 413-443.

19 Sobre los factores de este nuevo orden europeo, DURAND, Y. (1990): Le nouvel ordre européen nazi, 1838-1945. Bruxelles. Complexe. Sobre los antecedentes en otros países de esta concepción totalitaria de Europa, GONZÁlEZ CALLEJA, E.: «En busca del continente perdido: los intelectuales filofascistas en la Europa mediterránea y la defensa de Occidente en los años de entreguerras", en Mélanges offerts au Professeur Guy Mercadier. Aix-en-Provence, 1998, pp. 325-354 y GARCÍA PÉREZ, R.: «La idea de la "Nueva Europa" en el pensamiento nacionalista español de la inmediata postguerra, 1939-1944", Revista del Centro de Estudios Constitucionales, 5, 1990, pp. 203-240.

20 En su conocido discurso en la Universidad de Zurich en septiembre de 1946. Extractos en BossuAT, G.: Les fondateurs..., p. 102.

21 Algunos datos de todos ellos en Ibídem, pp. 95-118. Para mayor información, LIPGENS, W. (1982): A History or European Integration, vol 1: The Formation of the European Unity Movement, 1945-1947. Oxford, Clarendon, así como LOTH, W y LIPGENS, W. (Eds.): Documents on the History of Europen Integration. Berlin, De Gruyter, vols. 3 у 4, 1991 у 1995.

22 Una clara exposición del complejo organigrama de la OTAN, en BARBÉ, E. (1984): España y la OTAN. La problemática europea en materia de seguridad. Barcelona, Laia, pp. 27-49.

23 Interesantes reflexiones al respecto, DeIGHTON, A.: "Une maladie imaginaire. Le dilemme euroéen de la Grande-Bretagne», en Reflexions sur l'Europe. Sous la direction de B. Beutler, Bruxelles, Complexe, 1993, pp. 68-69.

24 RÉAU, obr. cit., pp. 203-224.

25 Una amplia exposición del tema en BossuAT, G. (1992): L'Europe occidentale à l'heure américaine, 1944-1952. Le plan Marshall et l'unité européenne. Bruxelles, Complexe.

26 Organigrama institucional y ejecutivo en BossuAT, G., obr. cit., pp. 140-141.

27 Bossuat, G., obr. cit., p. 135, citando a MélAndRI, P.: Les États-Unis face à l'unification de l'Europe, 1945-1954. Paris, Pedone, 1980.

28 DuRAND, J.-D. (1995): L'Europe de la démocratie chrétienne. Bruxelles, Complexe, p. 152 .

29 Sobre esta institución, Monnet, J. (1985): Memorias. Madrid, Siglo XXI edit., pp. $399-410$.

30 Bossuat, G.: Les fondateurs..., p.209 
31 Europe brisée, Europe retrouvée. Nouvelles réflexions sur l'unité européenne au XXe siècle. Sous la direct. de R. Girault et de G. Bossuat. Paris, Publ. e la Sorbonne, 1994, pp. 410-411.

$32 \mathrm{Al}$ respecto, Menudier, H. (1993): Le Couple franco-allemand en Europe. Arnières, Public. de l'Intitut Allemand.

33 Véanse las interesantes propuestas al respecto de ELIAS, N. (1988): $E l$ proceso de la civilización. Investigaciones sociogenéticas y psicogenéticas. México..., FCE, especialmente pp. 57-67.

$34 \mathrm{Al}$ respecto, KAHN-ACKERMANN, G.: «Quelques aspects de la politique européenne allemande", en Réflexions...., pp. 23-31

35 Interesantes reflexiones sobre su contexto en MAIER, H.: «Robert Schuman et les débuts de la réconciliation franco-allemande comme condition de l'union européenne», en Réflexions...., pp. 33-53.

36 Datos sobre el plan en Institut Charles de Gaulle (1992): De Gaulle et son siècle, tomo V: L'Europe. Actes des journées internationales.... Paris, Documentation Française-Plon, 1992. Testimonios de primera mano en Prate, A. (1995): La France en Europe. Paris, Economica, pp. 247-163.

37 MonNeT, J. (1985): Memorias, p. 280.

$38 \mathrm{El}$ ya citado alto funcionario francés ante las instituciones comunitarias, participante desde 1958 hasta la década de los 80 en todo el proceso negociador comunitario sobre el sistema aduanero, PRATE, A., obr. cit., p. 359.

39 Prate, A., obr. cit. p. 318.

40 BASSOLS, R. (1995): España en Europa. Historia de la adhesión a la CE, 1957-85. Madrid, Política Exterior, p.93.

41 Citado por Prate, A., obr. cit., p. 21.

42 Un principio según el cual la Comisión debe limitarse a aquellas funciones que por novedad o por su carácter supranacional no se encuentran cubiertas por las políticas nacionales, Millon-Delson, Ch. (1993): Le principe de subsidiarité. Paris, PUF.

43 Datos sobre estas etapas iniciales de la relación España/Comunidades Europeas en SÁNCHEZ-GiJón, A. (1973): El camino hacia Europa. Negociaciones España-CEE. Madrid, Edic. del Centro y del mismo autor (1975): Europa, una tarea inacabada. Barcelona, Planeta-Editora Nacional. Igualmente MoRENo JUste, A. (1998): España y el proceso de construcción europea. Barcelona, Ariel e Idem (1998): Franquismo y construcción europea, 1951-1962. Madrid, Tecnos. También, algunos artículos de España, Francia y la Comunidad Europea... Edic..... de ÉtIENVRE, J.-P. y URQUIJO GoITIA, J. R. Madrid, Casa de Velázquez-CSIC, 1989 y de Les Intellectuels et l'Europe de 1945 à nos jours. Sous la direction de A. BACHOUd, J. Cuesta y M. TREBitsCh. Paris, Publ. Universitaires Denis Diderot, 2000, especialmente los de L. Delgado y M. SAMANiEgo.

44 Sirvan como ejemplos los siguientes análisis sobre las amplias perspectivas abiertas a España en esta fase europea: España-Europa, número monográfico de Sistema, 86-87, noviembre, 1988; 1993; España ante el Mercado Único, S. M. RUESGA (Coord.). Madrid, Edic. Pirámide, 1989; España y la Otan. Textos y Documentos. Edic. de C. del Arenal y F. Aldecoa. Madrid, Tecnos, 1986.

45 M. A. Egido Leon,M. A. (1987): La concepción de la política exterior española durante la II República. Madrid, 1987, p. 58 y VARELA ORTEGA, J.: «De los orígenes de la democracia en España, 1845-1923", en Democracia, elecciones y modernización en Europa, siglos XIX y XX, S. Forner (Coord.). Madrid, Cátedra, 1997, p. 172.

46 SÁnCHEZ-GiJón, A. (1973): El camino....., p.24. 


\section{La construcción europea, en la perspectiva del siglo XX}

47 L'Union européenne et les defis de l'élargissement. Publié sous la direction de M. Telò. Bruxelles, Edic. de l'Université, s. f., pp. 7 ss.. Igualmente, Europe brisée........, p. 417.

48 Gnesotto, N. (1998): La puissance et l'Europe. Paris, Presses de Sciences Po, pp. 118-120.

49 Así lo anotaba el propio De Gaulle: Gaulle, Ch. de: Lettres, notes et carnets, 1961-1963, t. 9. Paris, Plon, 1986, p. 107

50 Debray, R. (1989): Tous azimuts: l'Europe stratégique. Paris, pp.133.

51 GNESOTTO, N., obr. cit., p. 21.

52 Interesantes observaciones al respecto en Reflexions..., p. 30 y GNESOTTO, N., obr. cit., p. 102. Para un planteamiento general, CoLSON, B. (1995): Europe: repenser les alliances. Paris, ISC-Economica.

$53 \mathrm{Al}$ respecto, Repenser l'Europe. Edité par TELÒ, M. y MAGnette, P. Bruxelles, Ed. Université, 1996, pp. 22.

54 Benda, J. (1933): Discours à la nation européenne. Paris, Gallimard, especialmente capítulo XI, p. 124 ss.

55 Véanse las interesantes observaciones al respecto de TELÒ, M. y MAGNETte, P.: «Les remises en cause de l'Europe politique depuis la chute du mur de Berlin: vers una démocratie supranationale et post fédérale», en Repenser..., pp. 7-26.

56 Al respecto, Repencer..., p. 4; GNESOTTO, N., obr. cit., pp. 93-94 y Vers une nouvelle Europe?. Towards a New Europe?. Publié sous la direct. de M. TELò. Bruxelles, Edic. de l'Université, 1992. Una interesante perspectiva sobre todas las cuestiones que acabamos de mencionar, en Entre Union et Nations. Sous la dir. de A.-M. le GloANnEC. Paris, Presses de Sciences Po, 1998.

57 Repenser..., p. 25.

58 Todos estos y otros aspectos vienen estudiados en uno de los libros-resumen del proyecto europeo de investigación que hemos mencionado: Identité et conscience européennes au XXe siècle. Sous la dir. de R. GIRAUlT. Paris, Hachette, 1994.

59 Esta perspectiva de la europeización de España es la que queda recogida en los trabajos de ABELLÁN, J. L.: «El significado de la idea de Europa en la política y en la historia de España", en España-Europa, Sistema, 86-87..., pp. 31-43; MARICHAL, J.: «La europeización de España (1898-1936), Ibídem, pp. 53-60 y VILLACORTA BAÑos, F.: "Les espagnols et le défi européen au XXe siècle», en Les Europe des Européens, sous la direction de R. GIRAult, avec la collaboration de G. Bossuat. Paris, Publ. de la Sorbonne, 1993, pp. 27-41. 